\title{
Absence of keratin 1 restricts the course of infection with lymphocytic choriomeningitis virus strain $\mathrm{MX}$
}

\author{
M. LABUDOVA ${ }^{1}$, M. ZDURIENCIKOVA ${ }^{1}$, A. FABIANOVA ${ }^{1}$, M. BARATOVA ${ }^{2}$, P. DITTE ${ }^{1}$, P. RADVAK ${ }^{1}$, \\ I. NEMCOVICOVA ${ }^{1}$, S. PASTOREKOVA ${ }^{1}$, J. PASTOREK ${ }^{1,3}$ \\ ${ }^{1}$ Department of Tumor Biology, Institute of Virology, Biomedical Research Center, Slovak Academy of Sciences, \\ Dúbravská cesta 9, 84505 Bratislava, Slovak Republic; ${ }^{2}$ BioScience Slovakia s.r.o., Bratislava, Slovak Republic; \\ ${ }^{3}$ Department of Chemistry, Faculty of Natural Sciences, University of SS. Cyril and Methodius, Trnava, Slovak Republic
}

Received October 16, 2018; accepted November 20, 2018

\begin{abstract}
Summary. - A rodent-transmitted enveloped lymphocytic choriomeningitis virus (LCMV) is an RNA virus causing persistent infection. During persistent infection, a unique strain MX of LCMV does not yield infectious virions, therefore it is not able to use a receptor for its dissemination, and spreads by cell-to-cell contacts. Virus can be transported to the neighboring cell by different cellular structures such as tunneling nanotubes or cytonemes. Using q-PCR, immunofluorescence, siRNA and western blot, we show that keratin 1 (K1) is essential for the persistent infection caused by LCMV strain MX, and its absence very effectively slows down the course of infection. In contrast, other LCMV strains, namely Clone 13 and Armstrong, which produce expression of $\mathrm{K} 1$, desmosomes in cells expressing K1 (42-MG-BA) but not in cells without K1 expression (NIH/3T3). We conclude that the presence of the virus enhances the K1 expression, while the presence of K1 protein potentiates the viral spread in persistently infected cells.
\end{abstract}

Keywords: lymphocytic choriomeningitis virus; keratin 1; persistent infection; desmosomes; virus transport

\section{Introduction}

Lymphocytic choriomeningitis virus (LCMV) is an RNA virus that belongs to the Arenaviridae family (Bowen et al., 1996). Virus contains two segments of ambisense-organized RNA encoding four genes. These genes encode five viral proteins: glycoprotein precursor (GPC), which is posttranslationally cleaved into two glycoproteins (GP1 and GP2), viral nucleoprotein (NP), zinc finger containing protein $\mathrm{Z}$ (ZP) and RNA-dependent RNA polymerase (L protein, L). The minimal infectious unit of the virus is ribonucleoprotein (RNP), which consists of two RNA segments encapsidated

E-mail: virulama@savba.sk; phone: +421-2-59302-439.

Abbreviations: ARM = LCMV strain Armstrong; Cl13 = LCMV strain Clone 13; GP = glycoprotein; $\mathrm{IF}(\mathrm{s})=$ intermediate filament(s); $\mathrm{K} 1$ = keratin 1; LCMV = lymphocytic choriomeningitis virus; MX = LCMV strain MX; NP = nucleoprotein by nucleoprotein, and RNA polymerase (Cornu and de la Torre, 2001).

LCMV is an RNA virus transmitted by common house mice (Mus musculus), a natural host and reservoir. However, the virus can also be transmitted by pet rodents (hamsters and guinea pigs). Humans are infected by the inhalation of aerosols from rodent excretes. A very important way of transmission is by organ or tissue transplantation, where infection may have fatal consequences (Schafer et al., 2013). Persistent infection of a donor patient may remain unrecognized and during the organ handling, when partial hypoxia of the organ occurs, the virus can be reactivated (Tomaskova et al., 2011). The reactivated virus generates acute infection after transplantation into immunosuppressed recipient, often ending with death (Schafer et al., 2013).

Persistent LCMV infection is characteristic for significant reduction of viral replication, restricted accumulation of viral glycoproteins at the cell surface and by formation of LCMV-specific defective interfering particles, which are 
generated early after the initiation of the infection (Buchmeier et al., 1980). The typical characteristics of LCMV persistent infection are accumulation and maintenance of high levels of intracellular LCMV RNAs and uncoupling of the synthesis of the major structural proteins NP and GP. $\mathrm{NP}$ is uniformly distributed throughout the cytoplasm of persistently infected cells, whereas surface expression of GP is significantly down-regulated (Meyer and Souther, 1997). Since GP is not present on the membrane, the assembly of virions cannot be completed, and virions are not released from the cell. The virus is thus not able to spread by a typical way of spreading via virion-receptor dependent manner.

During persistent infection, when the virions are not released into the extracellular space, virus can use a transmission by cell-to-cell contacts. For this transmission, complete virions or glycoproteins for receptor binding are not necessary. Thus, incomplete viruses or just RNP may be transmitted through the cellular protrusions (tunneling nanotubes), on the surface of the protrusions (cytonemes), with the help of cytoskeletal components (actin tails, e.g. Vaccinia virus), or by certain types of cellular junctions (gap junctions, Pseudorabies) (Labudova et al., 2018). These types of transmission have several advantages that favor the viral dissemination. The viruses do not require a receptor for the entry to the recipient cell; the transmission is faster because the recipient cell is in close proximity; the virus is protected from the immune system and virus neutralizing antibodies (Sherer and Mothes, 2008).

Desmosomes are highly specialized anchoring junctions that connect intermediate filaments (IF) to the sites of intercellular adhesion and facilitate the formation of a supracellular scaffolding (Green and Simpson, 2007). The junctions serve as anchors for cytoplasmic IF, fibers designed to withstand a high degree of mechanical strain (Coulombe and Omary, 2002). Transmembrane members of the cadherin family, desmogleins and desmocollins cooperate to form adhesive interface (Getsios et al., 2004). The cytoplasmatic tails of cadherins provide a binding platform for the proteins such as plakoglobin and plakophilins - other components of desmosomes (Schmidt and Jager, 2005). Desmoplakin, in turn, links the stress-bearing IF cytoskeleton to this specialized region of the plasma membrane (Hatsell and Cowin, 2001). IF proteins consist of a large family of nuclear (lamins) and cytoplasmatic (keratins, neurofilament, vimentin, desmin) cytoskeletal proteins (Steinert and Roop, 1988). Expression of IFs is tissue-specific: keratins in epithelial cells, vimentin in mesenchymal cells, desmin in muscles and neurofilaments in neuronal cells (Ku et al., 1996). The largest subfamily of IFs, namely the keratins (Moll et al., 1982) (K1-K20), have several biological and clinically relevant features. Epithelial tissues express at least one type I (K9-K20) and one type II (K1-K8) keratin in a cell-specific manner. Simple-type epithelia (liver, intestine, exocrine pancreas), for instance, express $\mathrm{K} 8 / \mathrm{K} 18$, and keratinocytes express K5/K14 in the basal proliferative compartment or $\mathrm{K} 1 / \mathrm{K} 10$ in the suprabasal differentiated compartment (McLean and Lane, 1995).

We have already proved that NP of LCMV MX strain uses $\mathrm{K} 1$ for transport to the desmosomes and to close proximity of the neighboring cell to allow for better cell-to-cell transmission (Labudova et al., 2009) and proposed several types of transport (Labudova et al., 2018). In this paper, using cells without $\mathrm{K} 1$ expression $(\mathrm{NIH} / 3 \mathrm{~T} 3)$ or with restricted $\mathrm{K} 1$ expression (42-MG-BA), we show that the absence of K1 slows down the viral transmission during persistent infection (strain MX) but it is not essential during acute infection (strain Armstrong and Clone 13).

\section{Materials and Methods}

Viruses and cells. LCMV strain MX is present in HeLa/MX cells permanently maintained in dense cultures (Reiserová et al., 1999). Strain Armstrong (ARM) was obtained from Dr. Boris Klempa, Institute of Virology, Biomedical Research Center, Slovak Academy of Sciences, Slovak Republic. Clone 13 (Cl13) was obtained from Dr. Jana Tomaskova, Institute of Virology, Biomedical Research Center, Slovak Academy of Sciences, Slovak Republic. HeLa/MX is a HeLa cell line infected by cell-free extract of MaTu cells (cells, which are persistently infected with LCMV strain MX) that was prepared by the procedure of van der Zeijst et al. (1983). The cells were cultured in complete DMEM medium (Lonza, Belgium) with $2 \mathrm{mM}$ L-glutamine supplemented with $10 \%$ fetal bovine serum (Lonza) and $160 \mu \mathrm{g} / \mathrm{ml}$ gentamicine (Lek, Slovenia) in humidified air atmosphere at $37^{\circ} \mathrm{C}$ in the presence of $5 \% \mathrm{CO}_{2}$. The cultures were maintained at high cell density to allow for easier virus transmission via cell-to-cell contacts (Zavada and Zavadova, 1991). For hypoxia experiments, the cells were incubated in hypoxia in Ruskinn Sci-tive hypoxia workstation (Ruskinn, USA) with $2 \%$ of oxygen, $5 \% \mathrm{CO}_{2}$ and $37^{\circ} \mathrm{C}$ for $72 \mathrm{~h}$. NIH/3T3 cells (ATCC CRL-1658) are mouse embryonal fibroblasts from mouse sarcoma, which do not express keratin 1 and 10.42-MG-BA (DSMZ ACC-431) cells are neuronal glioma cell line, where only $0.1 \%$ of cells from the population are keratin-positive (Macikova et al., 1999).

Antibodies. Primary antibodies: undiluted media of M87, a mouse monoclonal antibody specific for nucleoprotein of LCMV strain MX (Pastorekova et al., 1992); anti-cytokeratin 1 (N-20) antibody (Santa Cruz, USA), dilution of 1:200; mouse monoclonal antidesmosomal protein clone ZK-31 (Sigma Aldrich, USA), dilution 1:300. Secondary antibodies: goat anti-mouse IgG conjugated with horseradish peroxidase, dilution 1:5,000 (Dako, Denmark); rabbit anti-goat IgG conjugated with horseradish peroxidase, dilution 1:5,000 (Dako); goat anti-mouse conjugated with Alexa Fluor 488, dilution 1:2,000 (Life Technologies,); rabbit anti-goat conjugated with Alexa Fluor 594, dilution 1:2,000 (Invitrogen, USA). 
Infection. We infected HeLa cells at $80 \%$ confluence plated in $6 \mathrm{~cm}$ Petri dish with LCMV strains Cl13 and ARM at MOI of 0.1. Adsorbing of the virus was done at room temperature (RT) for 90 min in PBS with 2\% FCS. The virus was removed, and the cells were cultivated in DMEM with $2 \%$ FCS. Infection with media was done by addition of $2 \mathrm{ml}$ of media from infected or control cells plated in $6 \mathrm{~cm}$ Petri dish to $80 \%$ confluent cells. The adsorption was done at RT for $90 \mathrm{~min}$. After the removal of the medium a fresh medium with $2 \%$ FCS was added.

Cell-free extracts. Cell-free extracts of HeLa/MX cells were prepared according the protocol by Laposova et al. (2017). HeLa/ MX cells grown in monolayer on $10 \mathrm{~cm}$ Petri dish, were washed in cold PBS (Sigma Aldrich) and scraped into $400 \mu$ lof deionized $\mathrm{H}_{2} \mathrm{O}$ and incubated for $15 \mathrm{~min}$ on ice with repeated shaking. The cells were then centrifuged at $900 \mathrm{rpm}$ at $4^{\circ} \mathrm{C}$ for $15 \mathrm{~min}$. Supernatant was diluted in 1:1 ratio with DMEM containing $4 \%$ FCS, filtered through $0.2 \mu \mathrm{m}$ filter and transferred onto NIH/3T3 or 42-MG-BA cells. The following day the medium with extract was exchanged for DMEM with 10\% FCS. The infected cells were left to grow to high density to allow for easier virus transmission via cell-to-cell contacts. Cells were then passaged and monitored by PCR and immunofluorescence.

RNA isolation. Cells grown on a $3.5 \mathrm{~cm}$ tissue culture dish were washed 3 times in PBS and $500 \mu$ of Instapure (Eurogentec, Belgium) were added. For isolation of RNA from media, we used $200 \mu \mathrm{l}$ of media and $500 \mu \mathrm{l}$ of Instapure. At this step, we have spiked the media with $2000 \mathrm{ng}$ of RNA from HeLa cells, for later quantification. One hundred microliters of chloroform were added, and samples were mixed and incubated for $15 \mathrm{~min}$ at $4^{\circ} \mathrm{C}$. After $15 \mathrm{~min}$ centrifugation at full speed, the upper phase was collected, and the same amount of isopropanol was added to the supernatant. Samples were incubated at $-80^{\circ} \mathrm{C}$ for $30 \mathrm{~min}$ and centrifuged at full speed for $15 \mathrm{~min}$ again. RNA was washed, by centrifugation at $7500 \mathrm{rpm}$ for $5 \mathrm{~min}$, with $70 \%$ ethanol followed by another wash with $96 \%$ ethanol. The pellet was air dried and resuspended in DEPC water. RNA concentration was measured on NanoDrop 2000 (Thermo Scietific).

RT-PCR, PCR, nested PCR and q-PCR. For RT-PCR we used 2000 ng of RNA mixed with $10 \mu \mathrm{l}$ of master mix (High capacity cDNA reverse transcriptase kit, Applied Biosystems, USA). Master mix consisted of $5 \mathrm{x}$ RT buffer, $100 \mathrm{mM}$ random primers, $100 \mathrm{mM}$ $\mathrm{dNTP}$ and DEPC water. Conditions for the reaction were as follows: $25^{\circ} \mathrm{C}$ for $10 \mathrm{~min}, 37^{\circ} \mathrm{C}$ for $120 \mathrm{~min}$ and $85^{\circ} \mathrm{C}$ for $5 \mathrm{~min}$. To detect different viral genes, we used different sets of primers (Microsynth AG, Switzerland) shown in the Table 1. We used Dream Taq Green PCR master mix (Thermo Scientific, USA) with $100 \mathrm{mM}$ specific primers, $1 \mu \mathrm{l}$ of cDNA and water. The conditions for PCR were the same for all the genes: $95^{\circ} \mathrm{C} 3 \mathrm{~min}$ and 35 cycles of $95^{\circ} \mathrm{C} 30 \mathrm{~s}, 60^{\circ} \mathrm{C}$ $40 \mathrm{~s}, 72^{\circ} \mathrm{C} 40 \mathrm{~s}$ and a final polymerization at $72^{\circ} \mathrm{C}$ for $7 \mathrm{~min}$. Primers "ARM" were also used for the strain Clone 13. In the second round of nested PCR we used $1 \mu$ of the product from the first reaction as template. For the first round of nested PCR we used "NP" primers
Table 1. Primers used in this study

\begin{tabular}{ll}
\hline Gene & Primer sequence (5'-3') \\
\hline NP & S: ACTCACAGACCTTGGTCTGCTTTA \\
A: TTGTGTTTCCCATGCTCTCCCC \\
S: AAATACCCAAATCTCAATGACCTTGA \\
A: CCTACAAGCTATGTATGGCCACC \\
GP MX & S: AACCAGTGCAGAACTTTTAGAGGTA \\
& A: GCAAGTCTTCTAGTGAGGAACTTTG \\
GP ARM & S: AGCCAGTGTAGAACCTTCAGAGGTA \\
& A: GCTAGTCTCCTAGTGAAGAACTTAG \\
L MX & S: AGCTGCTGTCTCGTTGTATAGAAAT \\
& A: ATACATGCCAACTTGTTAGTGTCCT \\
L ARM & S: AGTTGCTGTCACGCTGCATTGAAAT \\
& A: ATGCATGCCAATTTGTTAGTGTCCT \\
ZP MX & S: CCTGTGAGAGTACAGAGA \\
& A: GATATCTTCAGCTTGGTT \\
ZP ARM & S: TCGTGAGGCTGTCAGAAGTGGACCT \\
Actin & A: GATATCTTCAATCTGGTTGGTAATG \\
& S: CCAACCGCGAGAAGATGACC \\
& A: AGGATCTTCATGAGGTAGTCAGTC
\end{tabular}

and for second round "NP nested" primers (Table 1). Both reactions were run at the same conditions: $95^{\circ} \mathrm{C} 3 \mathrm{~min}, 33$ cycles of $95^{\circ} \mathrm{C} 30 \mathrm{~s}$, $60^{\circ} \mathrm{C} 40 \mathrm{~s}, 72^{\circ} \mathrm{C} 40 \mathrm{~s}$ and a final polymerization at $72^{\circ} \mathrm{C}$ for $7 \mathrm{~min}$. For q-PCR we used the cDNA diluted in ratio 1:30 in sterile water and "NP" primers (Table 1). For the reaction, we used Maxima SYBR Green/ROX qPCR master mix (Thermo Scientific), with $100 \mathrm{mM}$ specific primers, $2 \mu \mathrm{l}$ of 1:10 diluted cDNA and water. Q-PCR was performed in Stratagene Mx3005P with MxPro software (Agilent Technologies, Germany). All samples were analyzed in triplicates. Sample Ct values were normalized to $\beta$-actin as internal control.

Immunofluorescence. Cells grown in monolayer were washed 3 times with PBS and fixed by $2 \%$ paraformaldehyde at RT for 20 min and permeabilized by $0,2 \%$ Tween 20 for $5 \mathrm{~min}$. Cells were blocked by $3 \%$ bovine serum albumin (BSA, Applichem, Denmark) for $1 \mathrm{~h}$ at $37^{\circ} \mathrm{C}$. The primary antibody was diluted in $1 \%$ BSA in PBS with $0.02 \%$ Tween 20 (Sigma Aldrich) and incubated for $1 \mathrm{~h}$ at $37^{\circ} \mathrm{C}$. After washing three times for $10 \mathrm{~min}$ with $\mathrm{PBS} /$ Tween 20 , secondary antibody diluted in $1 \% \mathrm{BSA}$ in PBS/Tween 20 was added. Incubation was done at $37^{\circ} \mathrm{C}$ for $1 \mathrm{~h}$. For double staining, we incubated cells with each primary antibody separately and both secondary antibodies were applied together for $1 \mathrm{~h}$ at $37^{\circ} \mathrm{C}$. For nucleus staining, we used DAPI (4', 6'-diamidino-2-phenylindole; Sigma Aldrich) diluted 1:1000 and incubated for $5 \mathrm{~min}$. Samples were fixed in Fluoroshield mounting medium (Abcam, UK) and analyzed on Leica DM4500B upright fluorescent microscope with camera Leica DFC480 (Leica, Germany) or on Zeiss LSM510 
laser scanning confocal microscopy system mounted on a Zeiss Axiovert $200 \mathrm{M}$ inverted microscope. Images were taken with Plan Apochromat 63x/1.4 oil objective and scanned at scan speed 6, 1024 x 1024 pixels, 12 bit data depth with average mode $8 x$ line (Zeiss, Germany). The fluorescence signal from at least 100 cells was analyzed by ImageJ software. The standard deviations (SD) were evaluated. Significance was evaluated with two-tailed unpaired $t$ test (Student's $t$-test) with a P-value of $<0.05$ considered significant $\left({ }^{*} \mathrm{P}<0.05 ;{ }^{* *} \mathrm{P}<0.01 ;{ }^{* * *} \mathrm{P}<0.001\right)$.

Immunoprecipitation and SDS-PAGE. Protein extracts were prepared by lysis of cells in RIPA buffer (sodium deoxycholate (Sigma Aldrich), Triton X-100 (Sigma Aldrich), inhibitors of proteases (Roche Diagnostics GmbH, Germany)) for 15 min on ice followed by centrifugation at full speed for $15 \mathrm{~min}$. One hundred micrograms of extracts or undiluted media were incubated with primary antibody (M87) over night at $4^{\circ} \mathrm{C}$. Then 3 times PBS-washed Protein G sepharose 4 Fast flow (GE Healthcare, Sweden) was added and samples were incubated on rotation shaker at RT for $1 \mathrm{~h}$. Protein $\mathrm{G}$ sepharose was washed 3 times with PBS and resuspended in $2 \mathrm{x}$ Laemli with $10 \%$ beta-mercaptoethanol, boiled for $5 \mathrm{~min}$, cooled and centrifuged. Samples were loaded onto $10 \%$ SDS-PAGE and run over night at $40 \mathrm{~V}$.

Western blot. Separated proteins were transferred onto Porablot PVDF membrane (Macherey-Nagel, Germany) for $2 \mathrm{~h}$ at 300 $\mathrm{mA}$. Membrane was blocked in 5\% skimmed milk in PBS with $0.2 \%$ Nonidet P40 substitute Bioxtra, mixture of 15 homologues (Sigma Aldrich) over night at $4^{\circ} \mathrm{C}$. Primary antibodies M87 or anti-cytokeratin 1 antibody were added, and the membrane was incubated for $1 \mathrm{~h}$ at RT. After three washes with PBS/Nonidet $\mathrm{P} 40$, secondary antibody labeled with peroxidase was added. After another wash, membrane was incubated in enhanced chemiluminescence solution, incubated for $1 \mathrm{~min}$ and developed on X-ray film (Fujifilm, Japan).

Aggregation assay. Differently infected or uninfected cells were analyzed by aggregation assay. Cells were seeded onto a 6 well plate $(150,000$ cells/well) and left to grow for $24 \mathrm{~h}$ on a rotation shaker at $120 \mathrm{rpm}$. Cells were then analyzed under an inverted microscope Axiovert 40 CFL (Zeiss) with 10x objective (Zeiss).

siRNA. HeLa cells at $80 \%$ confluence seeded a day before, were transfected with K1 siRNA (Santa Cruz Biotechnology, Germany) and scrambled siRNA by Gene silencer siRNA transfection reagent (Genlantis, USA). After $48 \mathrm{~h}$, the cells were infected with cell-free extract from $\mathrm{HeLa} / \mathrm{MX}$ cells or with virus suspension in case of strains ARM and Cl13. As a control for siRNA transfection, we used scramble siRNA ( $\mathrm{HeLa} / \mathrm{Scr}$ ) and as a control for cell-free extract infection (Hela/MX C siRNA), cells which were infected at the same time and same extract inoculum as the transfected ones. HeLa cells were used as a negative control (HeLa), while $\mathrm{HeLa} / \mathrm{MX}$ cells were used as a positive control (HeLa/MX) for NP expression. For secondary antibody background control, we used cells labeled with secondary antibody only ( $\mathrm{NC} 2^{\circ} \mathrm{Ab}$ only). We used flow cytometry to analyze the number of infected cells by detecting the viral NP.
Flow cytometry. Confluent cells were washed, trypsinised and centrifuged at $900 \mathrm{rpm}$ for $1 \mathrm{~min}$. Samples were washed in PBS with $10 \%$ FCS to inactivate the trypsin. The cells were fixed by dropwise adding of $96 \%$ ethanol with gentle mixing followed by $30 \mathrm{~min}$ incubation at $4^{\circ} \mathrm{C}$ on the shaker. Fixed cells were washed again with versene with $10 \%$ FCS and left in the washing buffer. Cells were transferred into 96-well plate, centrifuged at $900 \mathrm{rpm}$ for $5 \mathrm{~min}$ and primary antibody M87 was added. After $10 \mathrm{~min}$ incubation at RT, the cells were centrifuged at $900 \mathrm{rpm}$ for $5 \mathrm{~min}$ and washed. A secondary anti-mouse antibody conjugated with AF488 was added and incubated for $10 \mathrm{~min}$ at $37^{\circ} \mathrm{C}$. Ten-minute incubation and centrifugation followed, and the cells were analyzed by Guava Easy Cyte plus flow cytometer (Guava technologies, Merck, Germany).

Sequence analysis. For the protein sequence analysis, we used protein sequences of LCMV strain MX (Acc. No. Y16308.1), strain ARM (Acc. No. M20869.1) and Clone 13 (Acc. No. DQ361065.1). Sequences were analyzed in Blast protein alignment (Altschul et al., 1990) and by homology modeling software Swis-model (Arnold et al., 2006).

\section{Results}

\section{Infection of cells with restricted expression or without} expression of keratin 1

We have recently showed that nucleoprotein of LCMV strain MX interacts with $\mathrm{K} 1$. We assume that the virus uses $\mathrm{K} 1$ as a scaffold for transport to the desmosomes, where the cells form tight contacts. The virus is then transported to the neighboring cell by some other means of transport (Labudova et al., 2009, 2018) The question was whether $\mathrm{K} 1$ is necessary for the infection or if the virus is able to overcome its absence.

We used two cell lines, mouse embryonic fibroblasts $\mathrm{NIH} / 3 \mathrm{~T} 3$, which do not express $\mathrm{K} 1$ and $\mathrm{K} 10$, and neuronal glioma cell line $42-\mathrm{MG}-\mathrm{BA}$, where only $0.1 \%$ of cells of the population are keratin-positive (Macikova et al., 1999). The $80 \%$ confluent monolayer of the cells was infected with MX, Cl13 or ARM strain of LCMV. For MX strain, we used cellfree extract to mimic the virus transport during persistent infection without using the receptor, where incomplete virions or RNP should be transported to the cytoplasm by endocytosis. Cells were then grown and passaged for 10 passages. We have collected cells and media for RNA extraction after each passage and looked at the NP presence by PCR or immunofluorescence. We did not observe NP presence in NIH/3T3/MX-infected cells by immunofluorescence (Fig. 1). We also did not detect NP or other viral genes (GP, Z, L) in the RNA samples from cells or media (Figs. 2, 3). On the other hand, the presence of NP in NIH/3T3 cells infected with $\mathrm{Cl} 13$ or ARM was significant already in the $2^{\text {nd }}$ passage by nested PCR (Fig. 2) and immunofluorescence (Fig. 1). 
p2
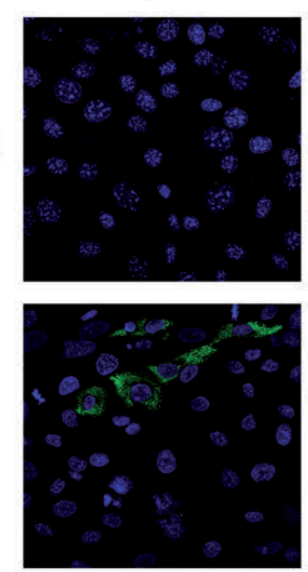

42-MG-BA/MX

$\mathrm{NIH} / 3 \mathrm{~T} 3 / \mathrm{Cl} 13$
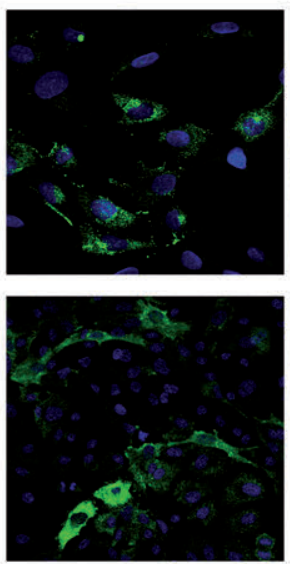

42-MG-BA/Cl13

NIH/3T3/ARM
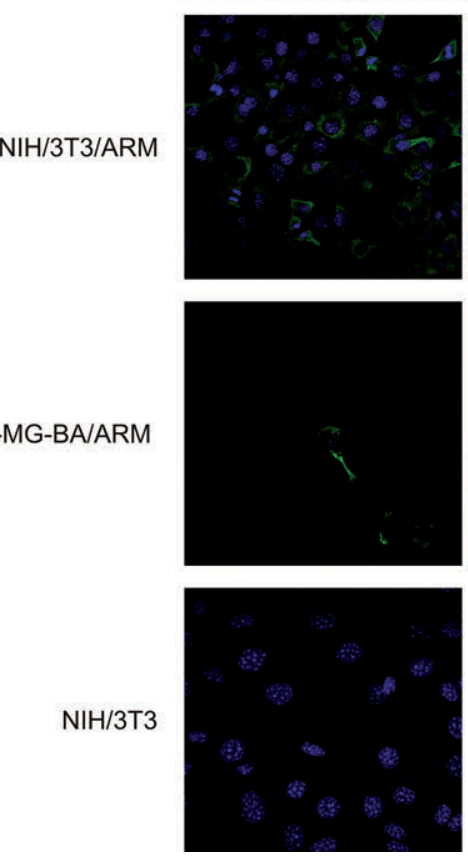

p4
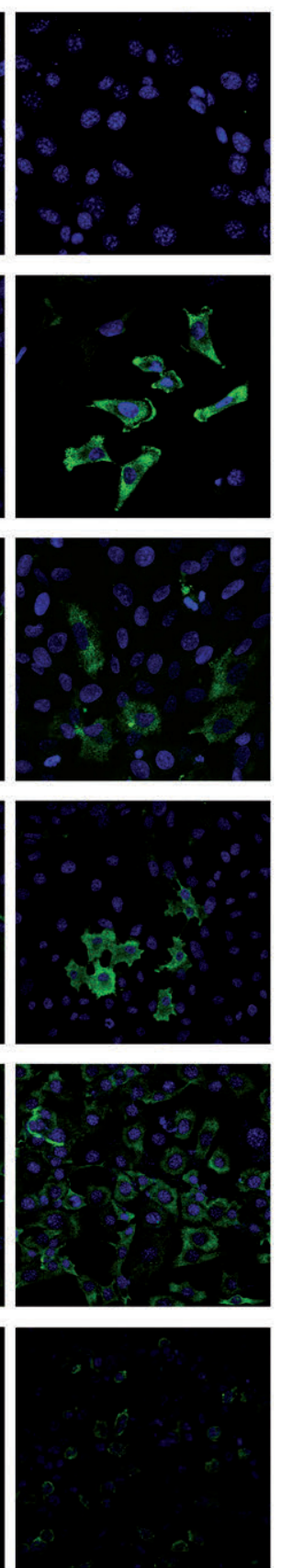

42-MG-BA/ARM

42-MG-BA p6
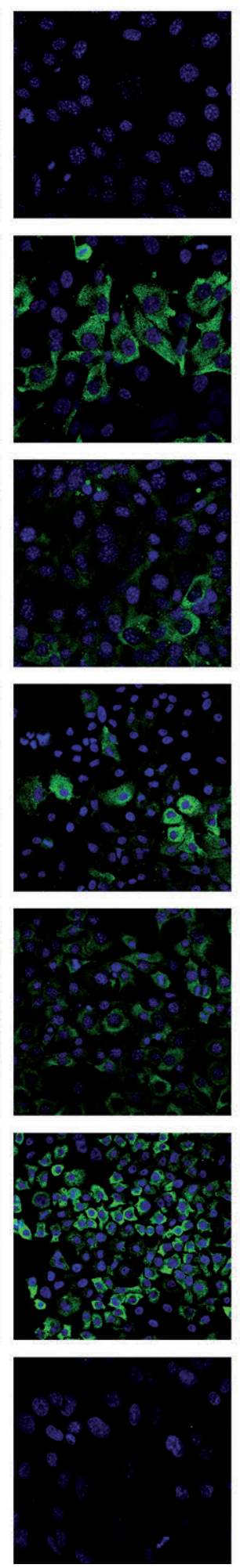

Fig. 1 p8
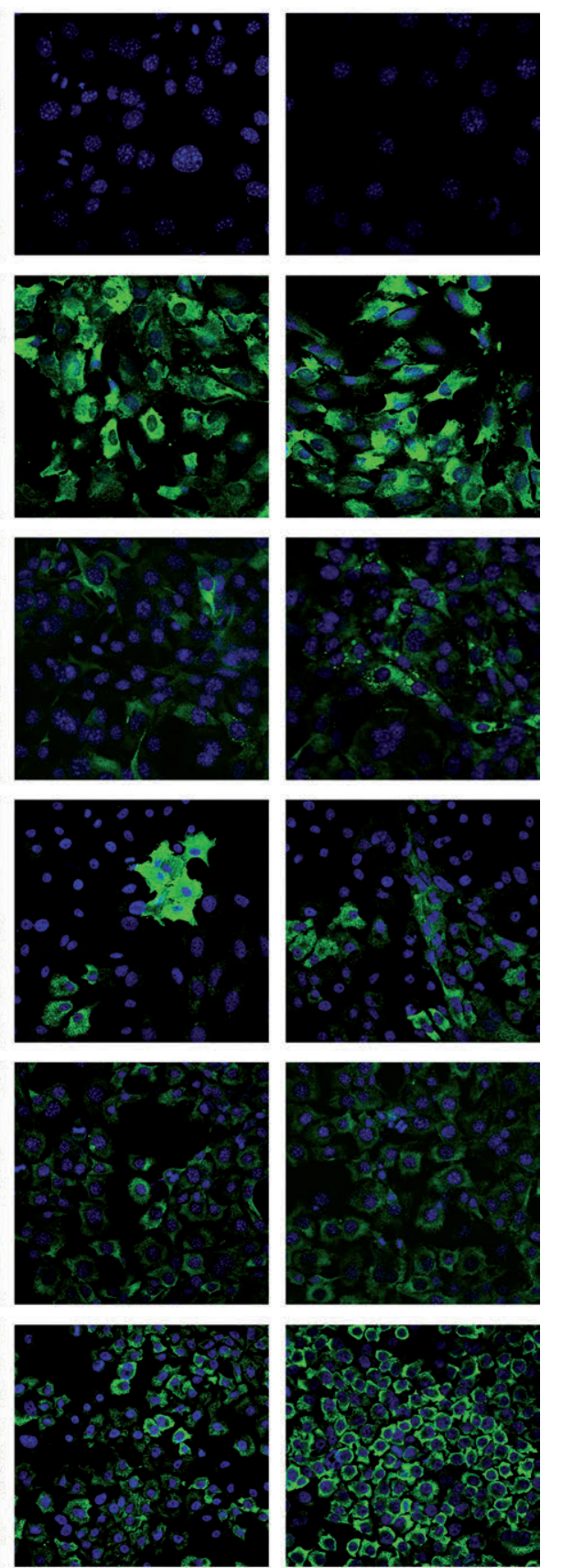

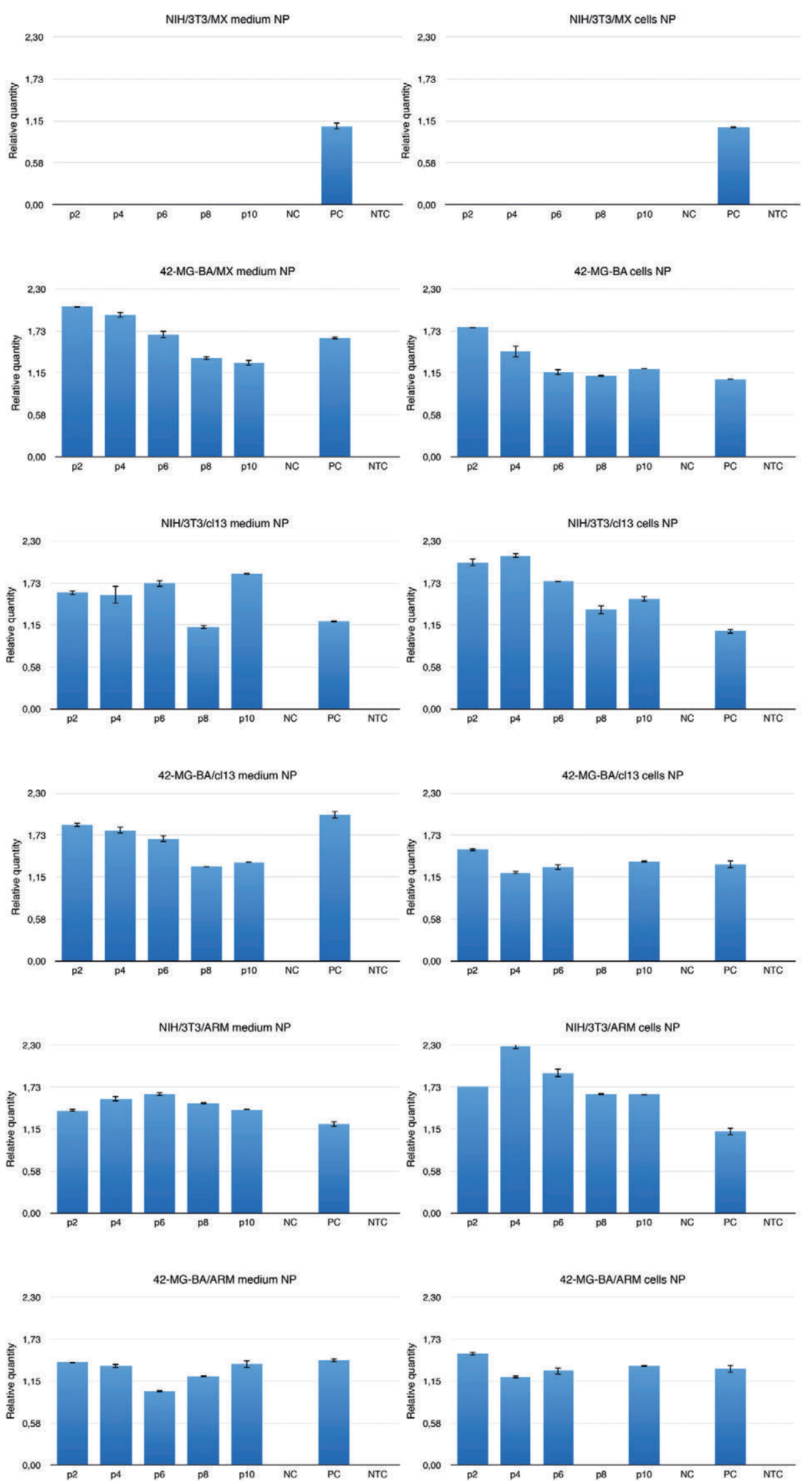

Fig. 2

Presence of NP gene in passages of infected cells - PCR

Nested PCR and q-PCR for detection of NP in passages $2,4,6,8$ and 10 in the NIH/3T3 and 42-MG-BA cells infected with strain MX, Clone 13 (Cl13) and Armstrong (ARM) of LCMV. The presence of NP was detected in cell-free media and in the cells. The $\mathrm{Ct}$ values of $\mathrm{NP}$ were normalized to actin. $\mathrm{PC}=$ positive control; $\mathrm{NC}=$ negative control; NTC = non-template control. 

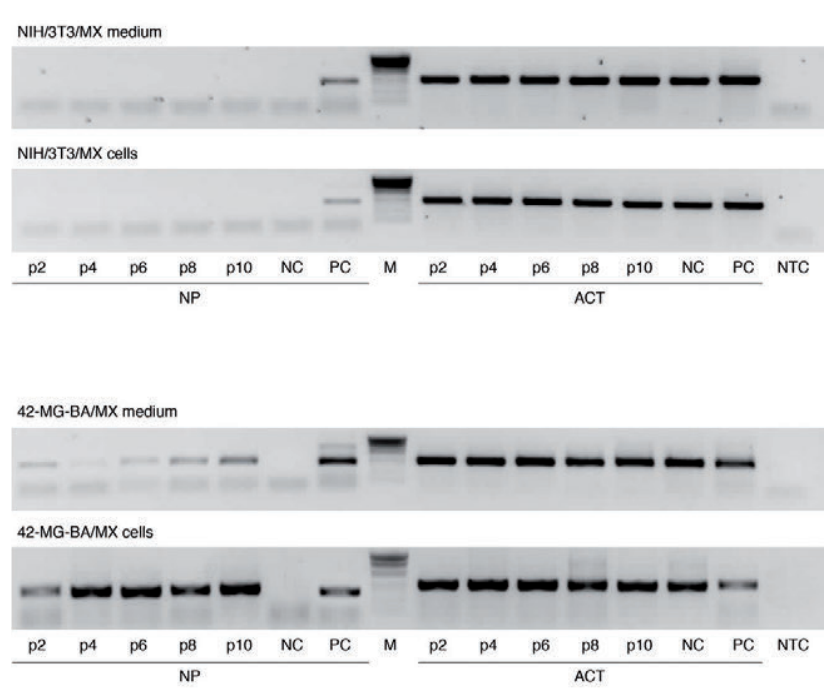

We have also detected the presence of other viral genes in cells and media. In addition, in glioma cell line 42-MG-BA, infected with any of the three viral strains, we were able to detect NP and other viral genes in media and in cells by nested PCR already in the second passage (Figs. 2, 3). The viral NP was also detected in second passage by immunofluorescence (Fig. 1). We have also confirmed the presence of the viral NP in the cell extracts of $\mathrm{NIH} / 3 \mathrm{~T} 3$ cells infected by $\mathrm{Cl} 13$ and ARM and in 42-MG-BA cells infected by all three strains in western blot and by immunoprecipitation of cell extracts and medium. However, we were not able to precipitate NP from the media of NIH/3T3 cells infected by Cl13 (Fig. 4).

\section{The change of cell morphology upon infection}

An interesting fact was observed after the infection of 42-MG-BA cells, when the change of morphology of 42-MGBA cells was promoted by the infection with strain $\mathrm{Cl} 13$ or ARM but not MX. Originally fibroblast-like cells changed their morphology after the infection to epithelial-like morphology (Fig. 5).

We have analyzed the expression level of truncated K1, which might be involved in the change of the morphology by western blot. NIH/3T3 cells did not express the truncated K1. However, we have observed down-regulation of truncated K1 in strain MX-infected 42-MG-BA cells, while cells infected with the strains $\mathrm{Cl} 13$ or ARM had similar expression as the control cells.

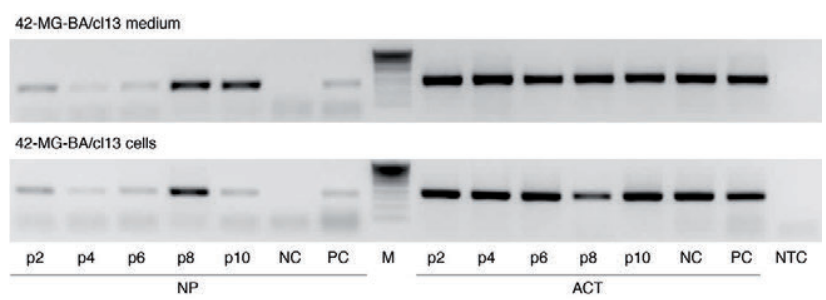

The presence of complete infectious virions of LCMV

To confirm the presence or absence of functional, complete or infectious virions, we collected the media from $\mathrm{NIH} / 3 \mathrm{~T} 3$ cells infected by each strain and used it as an inoculum for infection of HeLa cells. After the infection, cells were grown and passaged for at least 6 passages. The presence of NP was analyzed by immunofluorescence. The NP was present already at the first day after the infection by $\mathrm{Cl} 13$ or ARM but was not detected in the MX infected cells even after further ten passages (Fig. 6).
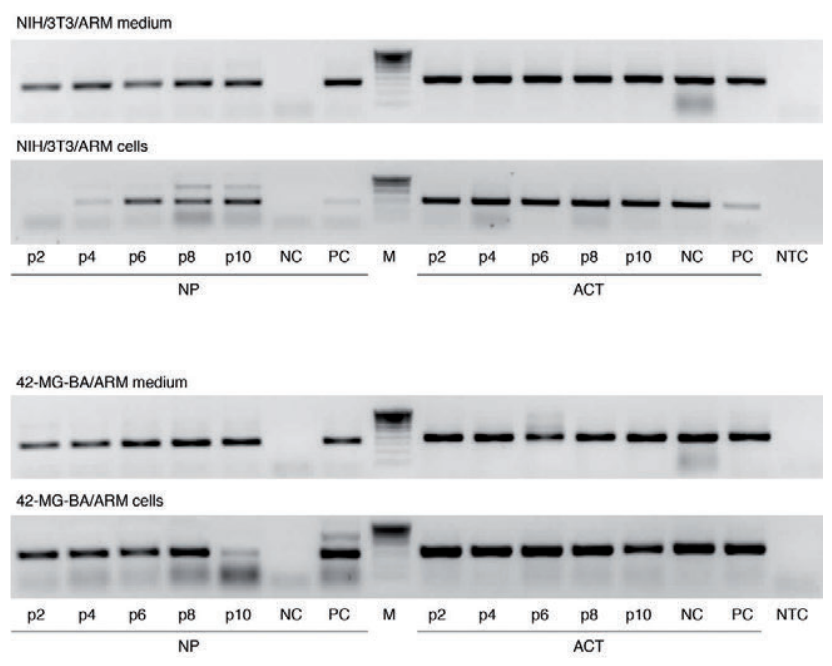

Fig. 2

\section{Reactivated strain MX of LCMV infects keratin deficient cells}

We have already shown that persistent LCMV strain MX is able to form complete and infectious virions after exposure to hypoxia (Tomaskova et al., 2011). To reactivate the strain MX, we cultivated the persistently MX-infected HeLa cells for $72 \mathrm{~h}$ in $2 \%$ hypoxia. We collected the media and used it as an inoculum to infect a new monolayer of NIH/3T3 and 42-MG-BA cells. Presence of the virus was detected by immunofluorescence with anti-NP antibody within 2 days post infection (Fig. 7). 


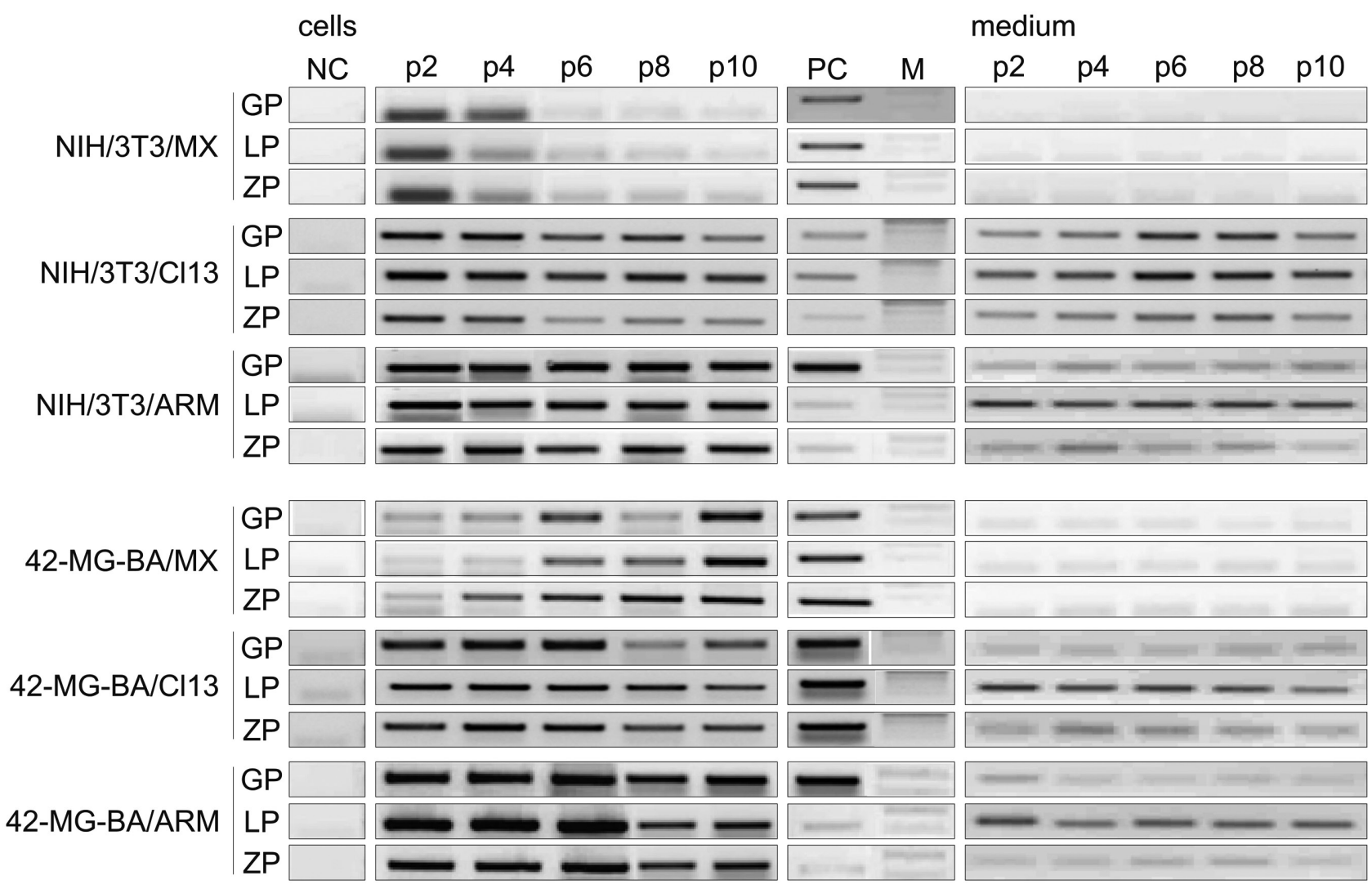

Fig. 3

Presence of other viral genes in infected cells and media - PCR

PCR for detection of viral glycoprotein (GP), RNA-dependent RNA polymerase (L protein, LP) and Z protein (ZP) in passages 2, 4, 6, 8 and 10 in the NIH/3T3 and 42-MG-BA cells infected with strain MX, Clone 13 (Cl13) and Armstrong (ARM) of LCMV. Viral genes were detected in cell-free media and in the cells. $\mathrm{PC}=$ positive control; $\mathrm{NC}=$ negative control; $\mathrm{M}=$ marker.

(a) Protein lysates

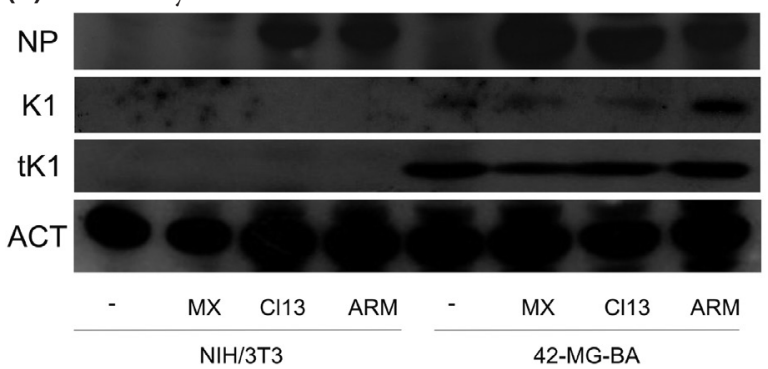

(b) IP of medium

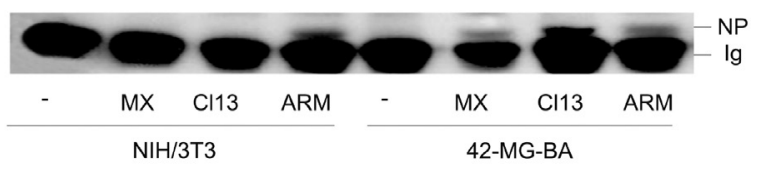

IP of cells

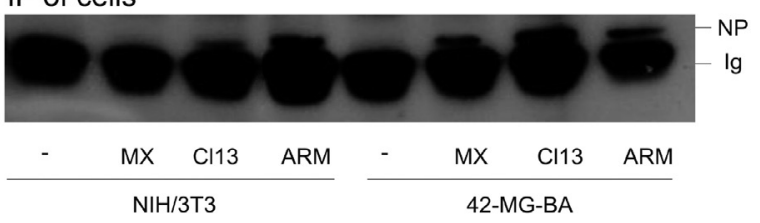

Fig. 4

Presence of NP and K1 in infected cells - Western blot (a) Western blot for detection of NP and $\mathrm{K} 1$ in the $20^{\text {th }}$ passage of the NIH/3T3 and 42-MG-BA cells infected with strain MX, Clone 13 (Cl13) and Armstrong (ARM) of LCMV. RIPA lysates of infected cells were subjected to SDS-PAGE and followed by western blot with anti-cytokeratin 1 and M87 antibodies. (b) Imunoprecipitation with M87 antibody from RIPA lysates and cell free media followed by SDS-PAGE and western blot. Ig = immunoglobulins. 

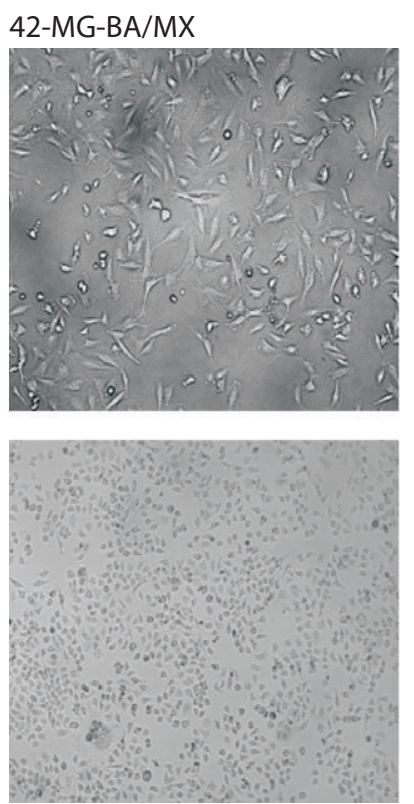

42-MG-BA/ARM

Fig. 5

Change of the cell morphology in infected cells Light microscopy of infected and control 42-MG-BA cells. Magnification 200x.

$1 \mathrm{dpi}$

HeLa infected with medium from NIH/3T3/MX
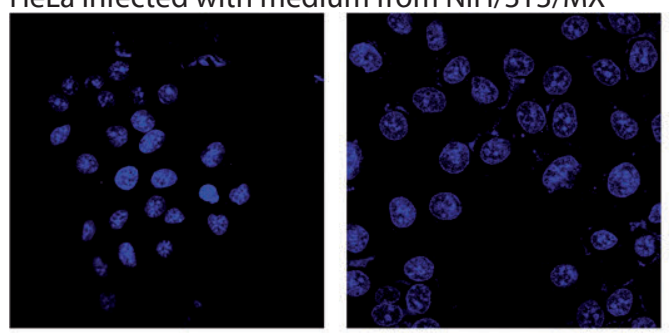

HeLa infected with medium from $\mathrm{NIH} / 3 \mathrm{~T} 3 /$ Clone 13
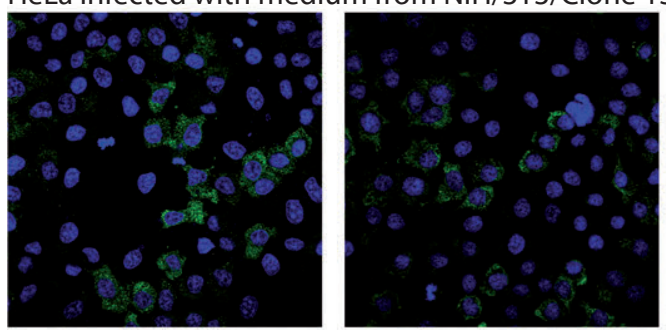

HeLa infected with medium from NIH/3T3/ARM
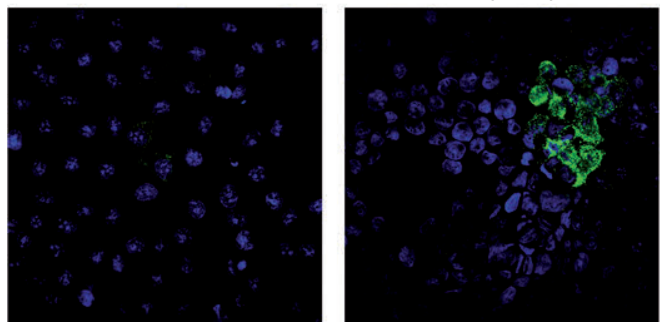

$\mathrm{NIH} / 3 \mathrm{T3}$
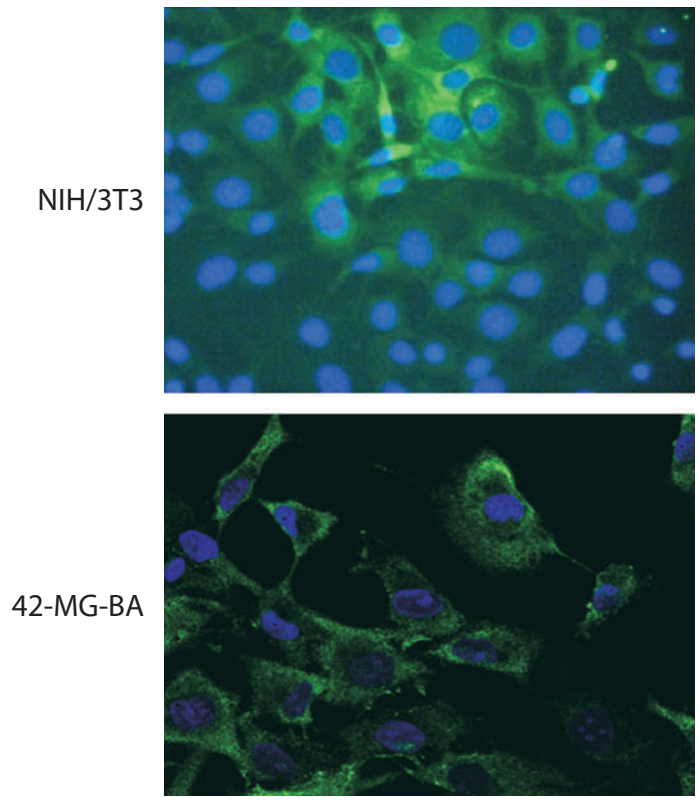

Fig. 7

Infection with hypoxic cell-free media

Imunofluorescence of NIH/3T3 and 42-MG-BA cells infected with media from HeLa/MX incubated in $2 \%$ hypoxia for $72 \mathrm{~h}$ after 1 day. Fluorescence staining was used for detection of NP with M87 antibody followed by secondary antibody labeled with AF 488 (green). Magnification 400x.
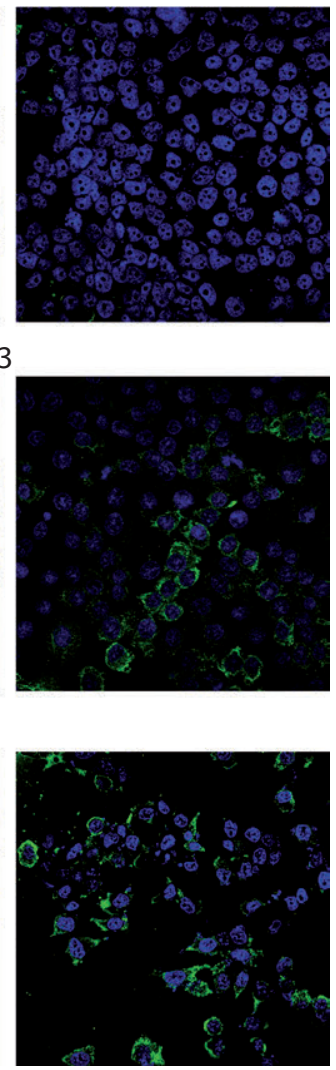

Fig. 6

Infection with cell-free media

Immunofluorescence of HeLa cells infected with medium from infected NIH/3T3 cells after 1, 2 and 6 days (dpi). Fluorescence staining was used for detection of NP with M87 antibody followed by secondary antibody labeled with AF 488. Magnification 400x. 
(a)

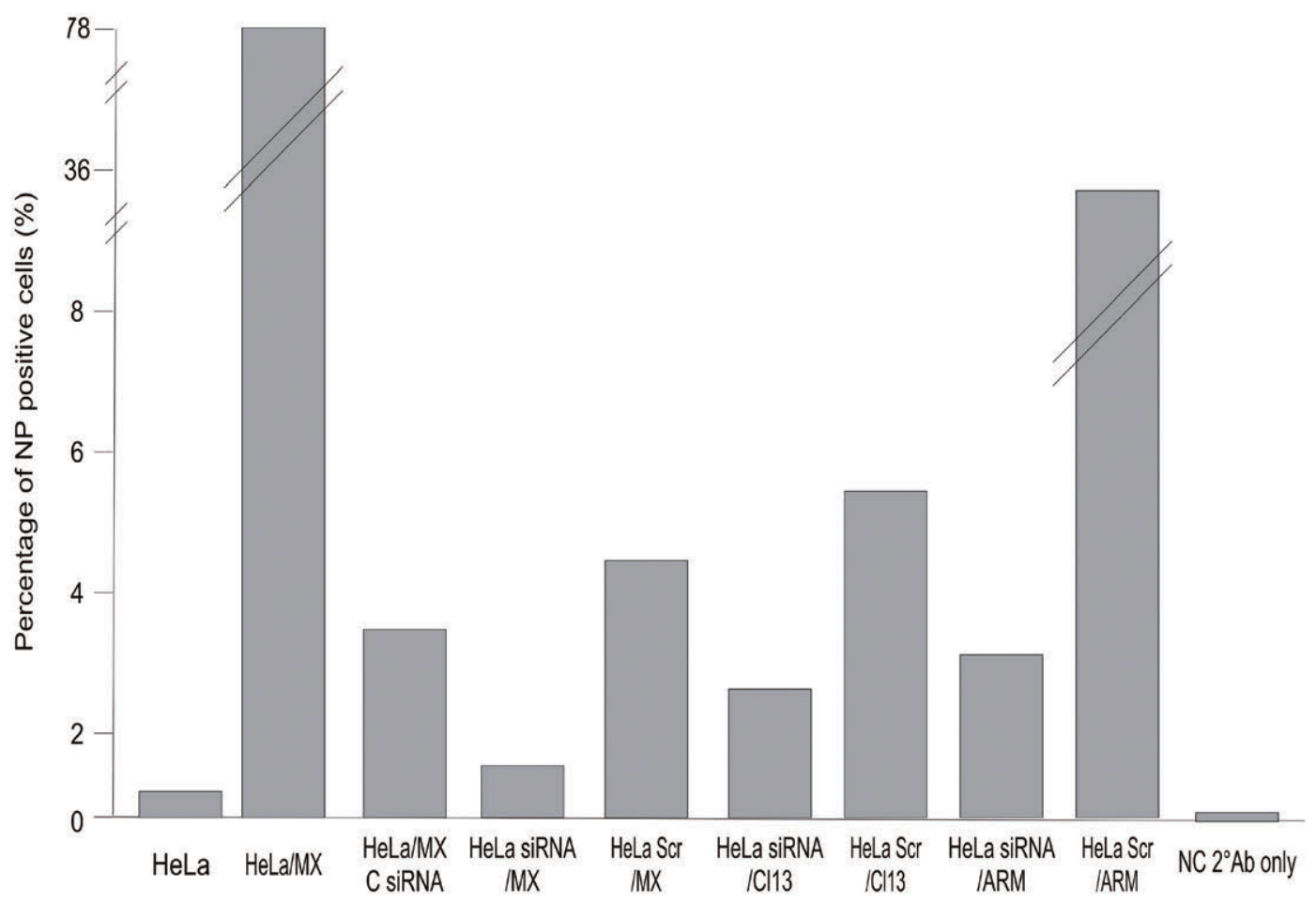

(b)
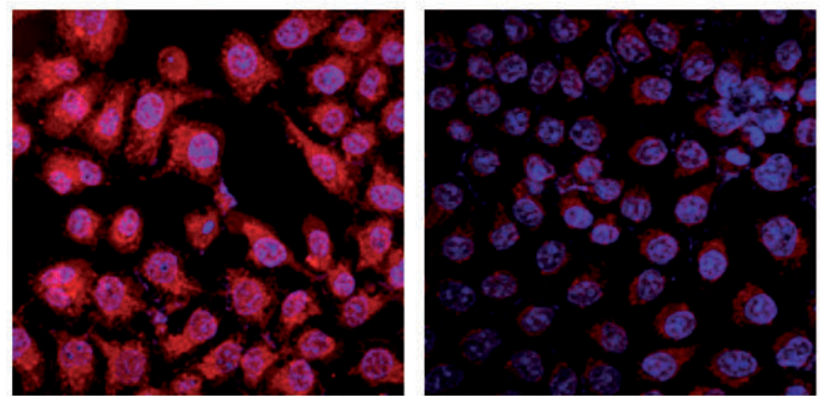

(c)

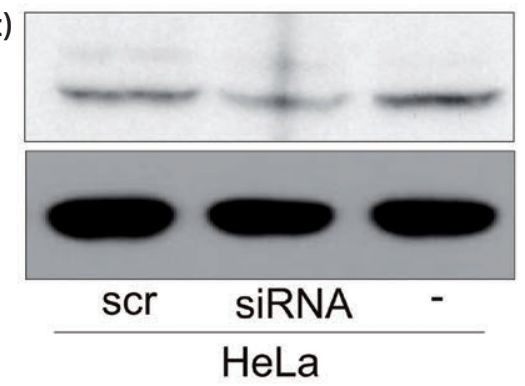

HeLa scr

HeLa SiRNA

Fig. 8

\section{K1 siRNA treatment}

(a) Flow cytometry of silenced K1 expression in HeLa cells with NP detected by M87 and secondary antibody conjugated with AF 488. HeLa cells were transfected with siRNA K1 and infected with LCMV strains MX (HeLa siRNA/MX), Clone 13 (HeLa siRNA/Cl13) and Armstrong (HeLa siRNA/ARM) after $24 \mathrm{~h}$. Control of silencing were cells transfected with scramble RNA $(\mathrm{HeLa} / \mathrm{Scr})$, which were also infected with all three strains. As a control for infection spread, we infected control HeLa cells at the same time with cell-free extract (HeLa/MX C siRNA). As a control for NP presence, we used HeLa cells (as negative control) and HeLa/MX cells (as positive control) and as a negative control of the antibody background we used cells labeled with secondary antibody only (NC $2^{\circ} \mathrm{Ab}$ only). (b) Immunofluorescence and (c) western blot of HeLa cells transfected with scramble RNA (HeLa Scr) and siRNA (HeLa siRNA) after $24 \mathrm{~h}$ after transfection with anti-K1 antibody.

\section{K1 siRNA silencing restricts infection by cell-free extracts}

To see if the cell-to-cell infection works after elimination of $\mathrm{K} 1$ from the cell, we have performed silencing with specific K1 siRNA. We have transfected HeLa cells with $\mathrm{K} 1 \mathrm{siRNA}$, and after $24 \mathrm{~h}$ cells were infected with all three LCMV strains. We have collected uninfected siRNA- and scramble-transfected HeLa cells as controls of silencing for western blot analysis (Fig. 8c). The cells were passaged for two passages and analyzed by flow cytometry for the presence of NP (Fig. 8a). At the same time, control cells were subjected to immunofluorescence (Fig. 8b). Flow cytometry showed that cells with silenced K1 were less infected than the control ones (Fig. 8a). 

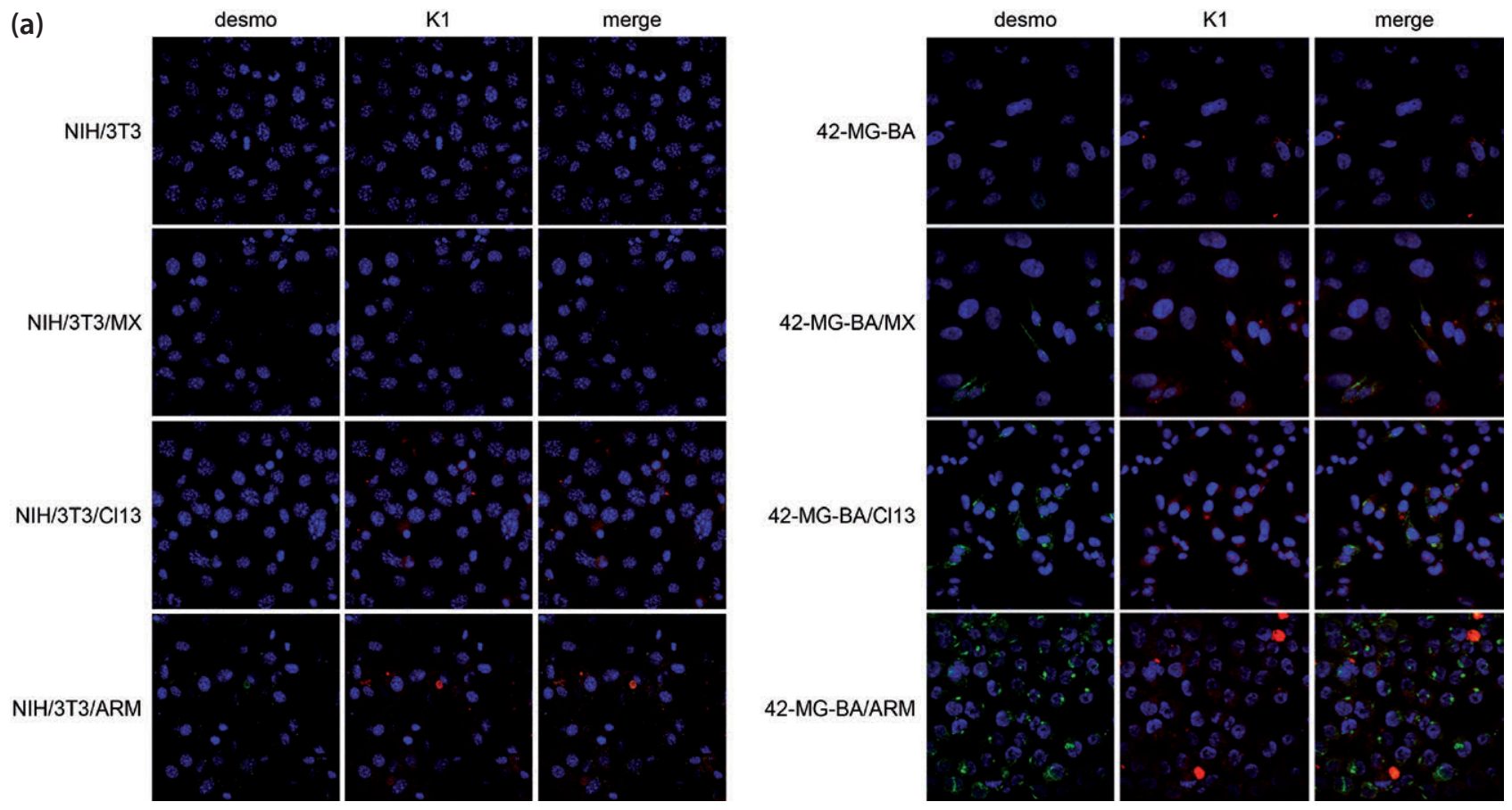

(b)
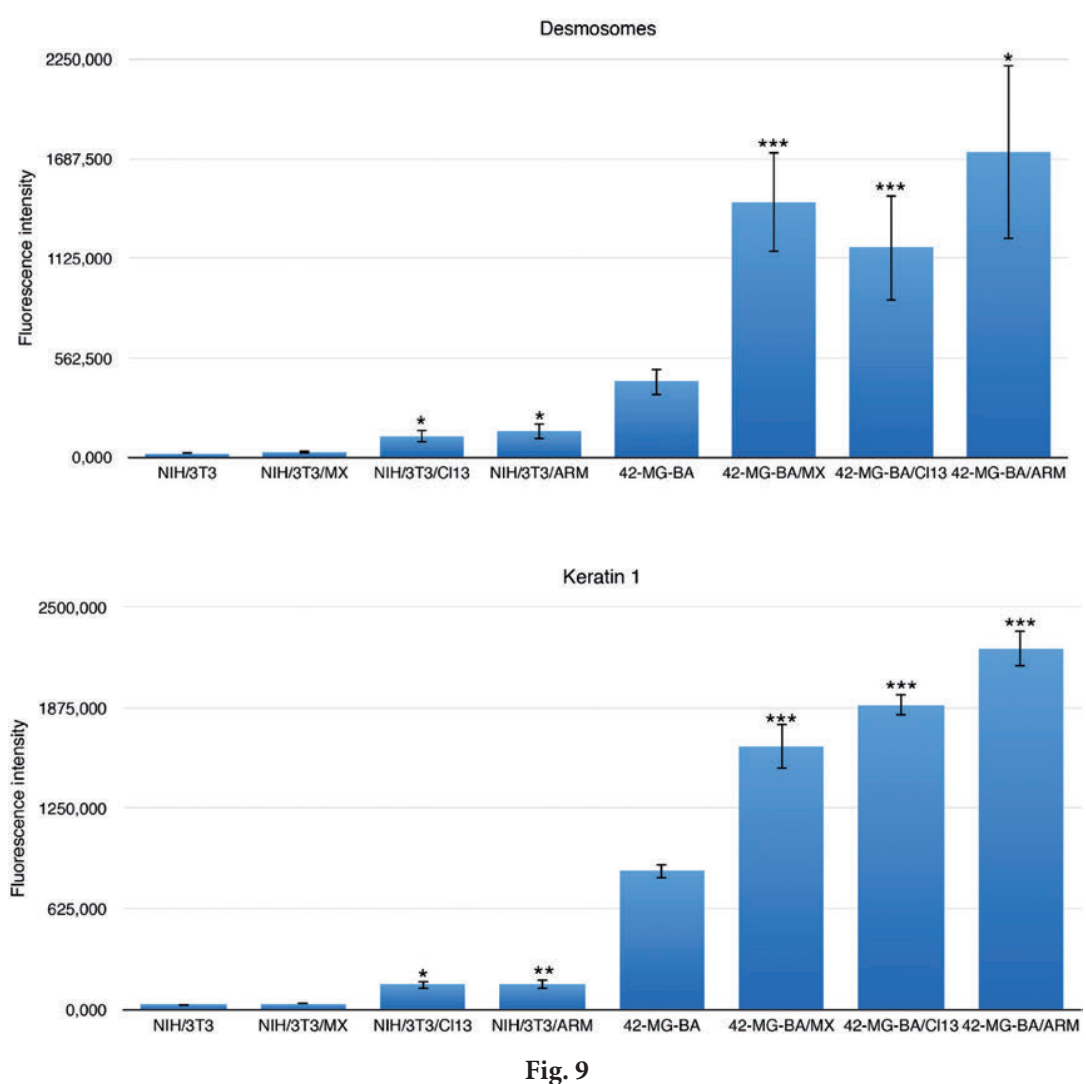

Expression of desmosomes and $\mathrm{K} 1$ in infected cells

(a) Immunofluorescence of desmosomes and K1 in the NIH/3T3 and 42-MG-BA cells infected with strain MX, Clone 13 (Cl13) and Armstrong (ARM) of LCMV. Desmosomes were detected by anti-desmosome antibody and secondary antibody labeled with AF488 (green). K1 was detected by anti-cytokeratin 1 and secondary antibody labeled with AF594 (red). Magnification 630x. (b) Graphs represent the fluorescence signal intensity of desmosomes and K1 from at least 100 cells of NIH/3T3 and 42-MG-BA infected or uninfected cells. Significance was evaluated with two-tailed unpaired t test (Student's $t$ test) with a P-value of $<0.05$ considered as significant (one asterisk) or $<0.001$ (three asterisks). 


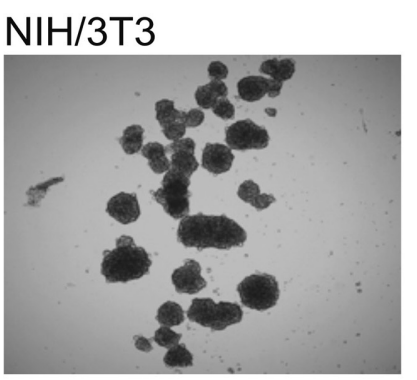

42-MG-BA
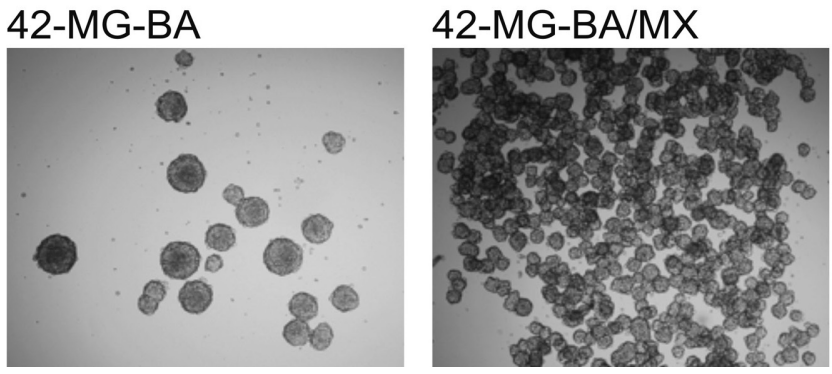

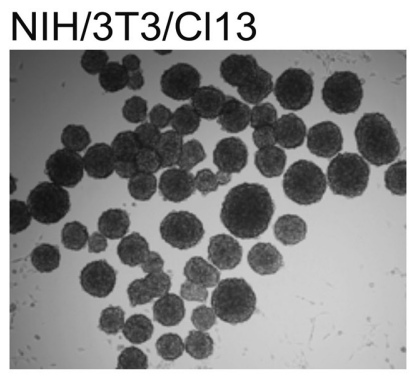

\section{2-MG-BA/Cl13}

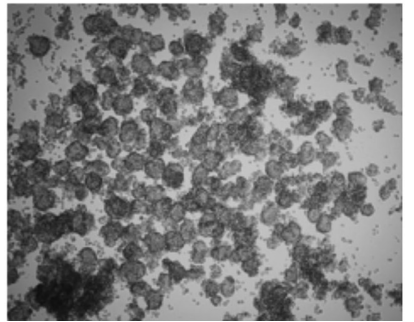

Fig. 10
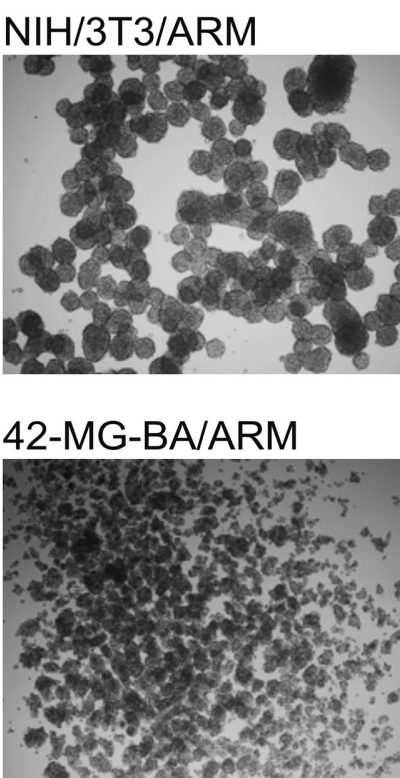

Aggregation assay of infected cells

Light microscopy of aggregation assay of NIH/3T3 and 42-MG-BA cells infected with strain MX, Clone 13 (Cl13) and Armstrong (ARM) of LCMV. Cells were immediately after seeding incubated on rotation shaker at $120 \mathrm{rpm}$ for $24 \mathrm{~h}$. Magnification 200x.

Higher expression of K1, desmosomes and adhesion molecules in infected cells with $\mathrm{K} 1$ expression

In previous work, we have shown that in MX-infected HeLa cells the expression of $\mathrm{K} 1$ and desmosomes is higher than in control cells (Labudova et al., 2009). We have analyzed NIH/3T3 and 42-MG-BA cells infected with all three strains for the presence of K1 and desmosomes by immunofluorescence (Fig. 9), and for the presence of adhesion molecules by aggregation assay (Fig. 10). In immunofluorescence we observed that uninfected and MX-infected NIH/3T3 cells do not express K1 or desmosomes (Fig. 9). NIH/3T3 cells infected with $\mathrm{Cl} 13$ or ARM had slightly elevated expression of both desmosomes and K1 (Fig. 9). There was only low expression of desmosomes and K1 in uninfected 42-MG-BA cells. High level of desmosomes and $\mathrm{K} 1$ was observed in these cells infected with all three strains (Fig. 9).

Uninfected NIH/3T3 cells form several aggregates of various elongated shapes. However, the infected cells form numerous and more globular aggregates. Cells infected with strain MX contained many of such irregular aggregates, however, also the globular ones. The other two strains formed mostly globular and larger aggregates. Although the 42-MGBA cells formed aggregates, there was a significant difference between infected and uninfected cells as well as between the different strains. Cells infected with LCMV strains Cl13 or ARM formed small aggregates, but these were very unstable and had the tendency to disintegrate. Moreover, the aggre- gates of the strain ARM were more disintegrated, than those of Cl13. On the other hand, the cells infected by strain MX formed compact, stable aggregates.

The MX-infected cells containing K1 form more stable aggregates than cells infected with other strains, meaning that they form stronger cell-to-cell contacts enabling for better cell-to-cell transmission of the virus.

\section{Sequence analysis of viral nucleoprotein}

The unique feature of the strain MX to utilize K1 for transmission could arise from its nucleotide sequence. To investigate the differences of the strains on the amino acid sequence base or the secondary structure, we have performed sequence comparisons.

We have compared the protein sequences of viral NP of LCMV strains MX and ARM/Cl13. LCMV strain ARM and Cl13 had 100\% amino acid identity. The sequence of strain MX had 24 changes in the amino acid sequence ( $96 \%$ identities) compared to other two sequences, according to the protein sequence alignment (Blast) (Altschul et al., 1990). The homology modelling (Swiss-model)(Arnold et al., 2006) of ARM/Cl13 and MX strains showed three sites that differed in the secondary structure. Although the results were based only on the domain homology, the three sites should be different enough to cause a significant change in the secondary structure (Fig. 11). These three sites could form a conformational epitope for K1 binding. 
(a)

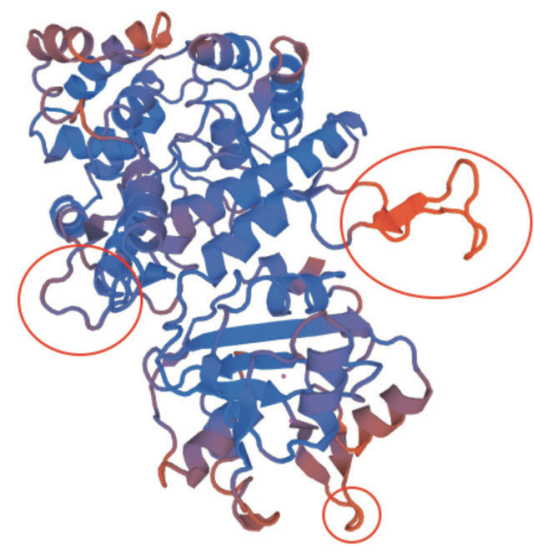

Clone 13/ARM

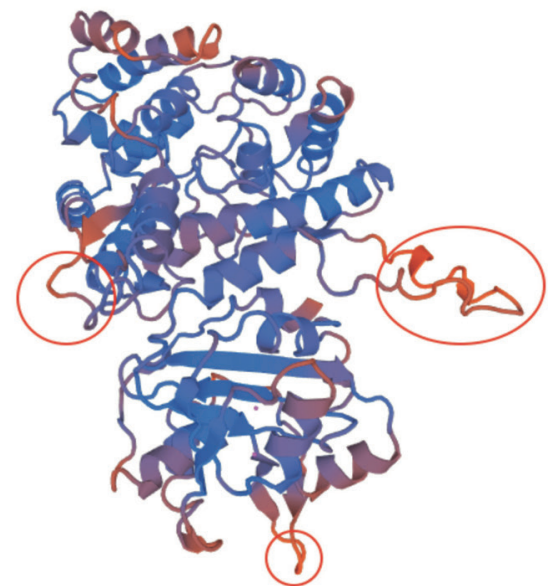

$\mathrm{MX}$

(b)

\section{Clone 13/ARM}
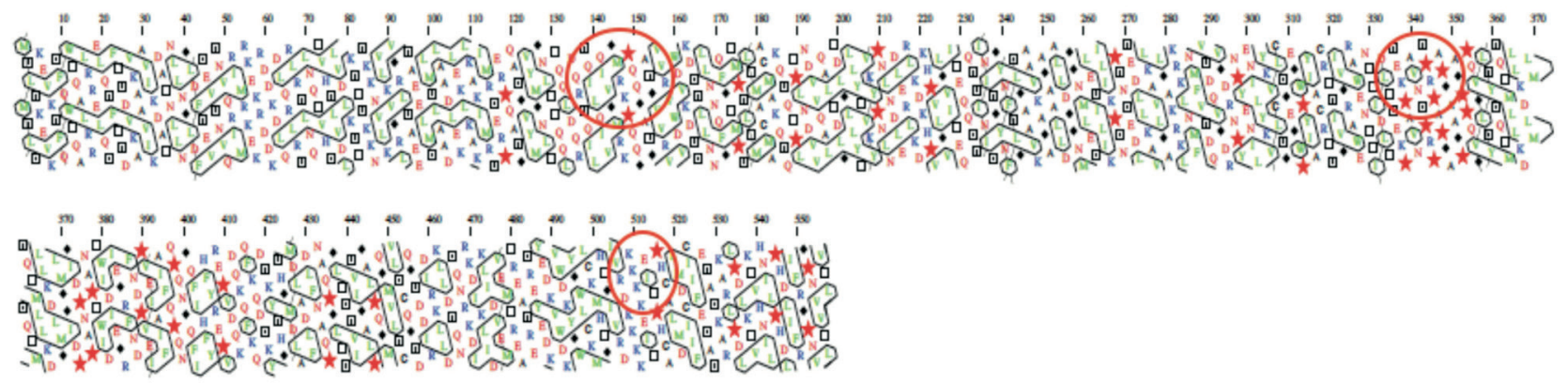

MX
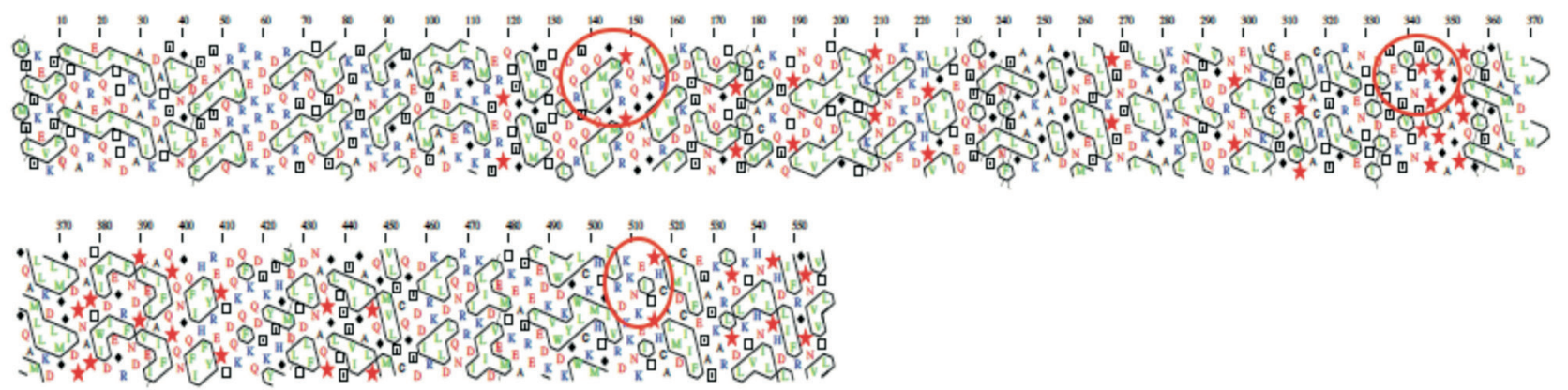

Fig. 11

Sequence analysis of viral nucleoprotein

Sequence analysis of viral NP of strain MX (Acc. No. Y16308.1), strain ARM (Acc. No. M20869.1) and Clone 13 (Acc. No. DQ361065.1). (a) Homology modeling in Swiss-model software and (b) hydrophobic cluster analysis. Red circles show the three most distinct sites of secondary structure of viral NP.

\section{Discussion}

For their transport to other cells viruses utilize different existing intercellular contacts and also modify or support the formation of different cellular protrusions or cytoskeletal components. Earlier, we have shown that LCMV strain MX interacts with the keratin 1 and thus improves cell-to-cell spread of the virus during persistent infection (Labudova 
et al., 2009). We were intrigued whether the absence of K1 in the cell will restrict the cell-to-cell spread.

LCMV causes a persistent infection. Many of the persisting viruses modulate and manipulate the cells and their metabolism or morphology to favor their replication and transmission.

Herein we present novel findings in the field of LCMV transmission and its course of infection. LCMV strain MX is a non-cytolytic virus that does not form functionally distinct virions and its transmission is mediated by cell-tocell contacts or cellular extracts, but not by cell-free filtered culture medium (Reiserová et al., 1999). Viral NP of MX strain binds the intermediate filament $\mathrm{K} 1$ and employs it as a scaffold for its distribution to desmosomes, where the cells form close contacts (Labudova et al., 2009). Further, the virus might be transported by cytonemes, tunneling nanotubes or propelled by actin to the neighboring cell (Labudova et al., 2018). In this work, we have focused on the impact of absence or restricted expression of K1 on LCMV transmission. We have used NIH/3T3 cell line that does not express $\mathrm{K} 1$ or $\mathrm{K} 10$. On the other hand, we have used glial $42-\mathrm{MG}-\mathrm{BA}$ cells that express $\mathrm{K} 1$ in $0.1 \%$ of the cell population (Macikova et al., 1999).

From our results we conclude that cells without any K1 can be infected with only two tested strains $\mathrm{Cl} 13$ or ARM of LCMV. Strain MX was not able to cause infection of cells without K1. Even after 10 passages we were not able to detect any of the viral genes (NP, GP, ZP, L) in cells and media. In addition, we were not able to infect HeLa cells with cell-free medium from NIH/3T3/MX cells, meaning that the infectious virions are not released into the media. This is consistent with the absence of the viral NP in the media. In contrast, the presence of NP in MX strain-infected 42-MG-BA cells was detected already in the second passage in the cells and also in medium. Viral genes were detected only in cells and not in medium, which is due to the persistent character of the virus strain.

Other two strains, Cl13 and ARM, were able to infect both types of cells already in the second passage. NP and the other viral genes were present in the cells and also in media. In addition, the presence of functional virions was confirmed by infecting HeLa cells by the media.

Recently it has been shown that the strain MX in persistently infected cells is reactivated after incubation in hypoxia. Hypoxic transactivation is accompanied by production of infectious virus particles that are released to the medium, as is typical for acute or productive infections (Tomaskova et al., 2011). In accordance with this, we studied the ability of the MX strain to infect NIH/3T3 cells in a form of virion. Therefore, we have infected NIH/3T3 cells with media from $\mathrm{HeLa} / \mathrm{MX}$ cells incubated in hypoxia. We observed the presence of NP in the cells already 2 days post infection. This suggests that even the cells without keratin can be effectively infected by strain MX, but only with complete infectious virions, which are able to spread without use of $\mathrm{K} 1$.

To see the effect of eliminating the K1, we have used siRNA silencing. Since the silencing was not complete, we have observed the infection by strain MX, however it was much slower than in scramble-transfected control cells. Also, the infection by other two strains was slower. These results potentiate the theory that the presence of $\mathrm{K} 1$ is important for effective transmission of the virus during persistence.

Keratins 1 and 10 are the main cytoskeletal filaments during transition from the proliferative to the terminal differentiation stage of epidermal cells. Formation of the K1/ K10 intermediate filament network occurs in the cytoplasm of cells with a preexisting cytoskeleton composed of keratins 5 and 14 (Kartasova et al., 1993).

$\mathrm{K} 1$ was, as hypothesized, absent in NIH/3T3 cells and also in MX-infected NIH/3T3 cells. However, it was slightly elevated in ARM or Cl13 infected cells. 42-MG-BA cells had much stronger expression of $\mathrm{K} 1$ when infected with any of the strains. The presence of NP in NIH/3T3 cells in early passages was not able to induce the expression of $\mathrm{K} 1$, as we have presumed. Kartasova et al. reported that after the transfection of $\mathrm{K} 1 / \mathrm{K} 10$ into the $\mathrm{NIH} / 3 \mathrm{~T} 3$ cells, the cells contained dense filament bundles, suggesting that $\mathrm{K} 1$ and $\mathrm{K} 10$ were able to assemble into filaments in the environment of NIH/3T3 cells, although they could not produce a cytoskeletal network. In addition, other factors, which contribute to the filament network formation, are either not present in the NIH/3T3 cells, or the NIH/3T3 cells contain factors detrimental to cytokeratin network development (Kartasova et al., 1993). Since factors, which might be important for the filament assembly (e.g. desmosomes) as well as a proper anchoring of the keratin could be missing in nonepithelial cells, the network formation might not occur (Coulombe and Omary, 2002) as we have seen in NIH/3T3 infected cells. However, in the infected 42-MG-BA, where the K1 is already expressed, the virus probably enhances or stabilizes the expression of $\mathrm{K} 1$. This can also explain the change of the morphology of 42-MG-BA cells infected with Cl13/ARM. Infected NIH/3T3 cells, regardless of the virus strain, and 42-MG-BA cells infected by MX did not change their morphology. As we have mentioned above, this may have been due to the lower levels of $\mathrm{K} 1$ thus resulting in the inability to form a distinct cytoskeletal network in these cells, and failure to morphologically differentiate to epithelial-like cells. But other aspects may also play a role in the morphological changes.

The morphology of the cells, however, can be changed also by changes in regulation of $\mathrm{K} 1$ by the virus. For instance, in EBV-infected cells, the up-regulation of truncated K1 $(\mathrm{hHb} 1-\Delta \mathrm{N})$ was detected. The unstable truncated $\mathrm{K} 1$ protein inhibited some of the functions of the keratin cytoskeleton and interfered with transcription regulation. The authors assume that the up-regulation of truncated K1 may be a 
link between EBV and the low differentiated or anaplastic status of the carcinomas that carry the virus (Nishikawa et al., 2003). Cells 42-MG-BA infected with strain MX, which did not show any change of morphology, had lower expression of truncated $\mathrm{K} 1$ than the uninfected cells. It is possible that the LCMV interferes with the cytoskeleton and causes the opposite process (down-regulation) and stimulates the cell into differentiation.

It was also found that fibroblasts undergo morphological changes in response to TGF- $\beta$ and proliferate much faster (Wilkes et al., 2003). TGF- $\beta$ receptor signaling activates PAK2 homolog in fibroblasts by Smad2 and/or Smad3 independent pathway (Wilkes et al., 2003). PAK2 activation primarily occurs in response to a variety of stresses, such as exposure to ionizing radiation, hyperosmotic shock and serum starvation (Roig and Traugh, 2001). There may be a possibility that acute infection with LCMV induces the production of TGF- $\beta$, which then causes the morphological changes. However, this needs to be further investigated.

Desmosomes play an important role in LCMV infection. $\mathrm{K} 1$ binds to desmoplakin, a component of desmosomes. As we assumed, there was only minor elevation in expression of desmosomes in Cl13/ARM-infected NIH/3T3 cells, while there was no change in expression in MX infected cells. However, in infected 42-MG-BA cells, the K1 expression increased and the level of desmosomes was higher.

Aggregation assay mirrors the amount of the tight connections and state of different adhesion molecules in cells. Although the control cells are able to aggregate, we observed more aggregates in the infected cells. MX-infected NIH/3T3 cells form aggregates resembling those of control cells, larger, irregular, and unstable. Strain Cl13-infected cells formed aggregates to a higher extent and strain ARM, especially in 42-MG-BA cells (in NIH/3T3 only slightly), caused disintegration of the aggregates. The $\mathrm{Cl} 13$ and ARM strain infected cells formed globular aggregates without the presence of the irregular shapes. This is in consistence with the level of infection. In 42-MG-BA cells, the strain MX, as a persistent strain, which induces the expression of $\mathrm{K} 1$ and desmosomes, forms more junctions and intercellular contacts and, therefore, forms distinct and compact aggregates. The presence of more intercellular connections supports the dissemination of the persistent virus, even without the formation of the infectious virions. On the other hand, the strains Cl13/ARM, which in our results showed the presence of infectious virions, are capable of infecting the cells without utilization of intercellular connections, caused the disruption of the aggregates probably by the release of the virions. This is in consistence with the fact that the aggregates of more aggressive strain ARM were even more distorted than those of the strain Cl13. However, the aggregates of NIH/3T3 cells infected with Cl13/ ARM were not distorted as those of 42-MG-BA, since the level of their infection is much lower.
To explain the differences between these three strains that behave so differently, we have compared their amino acid sequences. The sequence of the strain MX was already characterized and revealed the change at amino acid 260 (phenylalanine (F) to leucine $(\mathrm{L})$ ) located in the viral spike GP1 protein, which is identical to the strain Cl13 (Tomaskova et al., 2008), but it differs from the strain ARM, where there is $\mathrm{F}$ at this position (Matloubian et al., 1990). The F260L mutation is essential for the persistence of the strain Cl13, and probably also of the strain MX (Sullivan et al., 2011). LCMV Cl13 was originally isolated from the spleen of mice infected with the ARM strain of LCMV (Ahmed et al., 1984). It differs from the parental strain by five nucleotides, two of which result in coding changes (Salvato et al., 1988).

In the protein alignment of NP, we have obtained three sites that distinguish strain MX from strains Cl13/ARM. These sites could be involved in the binding of the NP to K1. Moreover, we have previously constructed three constructs containing overlapping fragments of nucleoprotein. In a pulldown assay, all three fragments interacted with K1 (data not shown). Each of the three sites with the structural changes were located in the sequence of each fragment of NP. This suggests that these three sites could form a conformational epitope of MX NP for the interaction with K1. This interaction would enable a better distribution of the virus during persistent infection and makes the virus more dependent on the presence of $\mathrm{K} 1$.

The LCMV genus comprises strains of different nature such as strain ARM, causing acute infection; strain Cl13, a clone derived from strain ARM causing persistent infection; or a strain MX, causing persistent infection and producing infectious virions only under hypoxic conditions. From our results we conclude that the absence of $\mathrm{K} 1$ in cells $\mathrm{NIH} / 3 \mathrm{~T} 3$ hinders the infection of MX strain. The course of the infection of other two strains remains more or less unaffected by the absence of K1. Of all three strains, strain MX was the most affected by the absence of K1. We have also found three sites in the protein structure of the nucleoprotein of strain MX that could be responsible for the interaction with K1.

The knowledge of the persistence mechanism of the viruses, especially LCMV, because of its association with the problems during transplantation process (Schafer et al., 2013), or pregnancy is very important for the prevention and therapeutic purposes. Since cytoskeletal component K1 is not essential for the cell, it could be an adequate target for antiviral therapy.

Acknowledgments. Strain Armstrong (ARM) was obtained from Dr. Boris Klempa, Institute of Virology, Biomedical Research Center, Slovak Academy of Sciences, Slovak Republic. Clone 13 (Cl13) was obtained from Dr. Jana Tomaskova, Institute of Virology, Biomedical Research Center, Slovak Academy of Sciences, Slovak Republic. We thank our colleague Dr. Petra Bullova, PhD. for criti- 
cal reading and the grammar correction. This work was supported by VEGA-2/0146/12 grant from the Scientific Grant Agency of Ministry of Education of the Slovak Republic.

\section{References}

Ahmed R, Byrne JA, Oldstone MB (1984): Virus specificity of cytotoxic $\mathrm{T}$ lymphocytes generated during acute lymphocytic choriomeningitis virus infection: role of the $\mathrm{H}-2$ region in determining cross-reactivity for different lymphocytic choriomeningitis virus strains. J. Virol. 51, 34-41.

Altschul SF, Gish W, Miller W, Myers EW, Lipman DJ (1990): Basic local alignment search tool. J. Mol. Biol. 215, 403-410. https://doi.org/10.1016/S0022-2836(05)80360-2

Arnold K, Bordoli L, Kopp J, Schwede T (2006): The SWISSMODEL workspace: a web-based environment for protein structure homology modelling. Bioinformatics 22, 195-201. https://doi.org/10.1093/bioinformatics/bti770

Bowen MD, Peters CJ, Nichol ST (1996): The phylogeny of New World (Tacaribe complex) arenaviruses. Virology 219, 285-290. https://doi.org/10.1006/viro.1996.0248

Buchmeier MJ, Welsh RM, Dutko FJ, Oldstone MB: (1980) The virology and immunobiology of lymphocytic choriomeningitis virus infection. Adv. Immunol. 30, 275-331. https://doi.org/10.1016/S0065-2776(08)60197-2

Cornu TI, de la Torre JC (2001): RING finger Z protein of lymphocytic choriomeningitis virus (LCMV) inhibits transcription and RNA replication of an LCMV S-segment minigenome. J. Virol. 75, 9415-9426. https://doi.org/10.1128/ JVI.75.19.9415-9426.2001

Coulombe PA, Omary MB (2002), Hard' and ,soft' principles defining the structure, function and regulation of keratin intermediate filaments. Curr. Opin. Cell Biol. 14, 110-122. https://doi.org/10.1016/S0955-0674(01)00301-5

Getsios S, Huen AC, Green KJ (2004): Working out the strength and flexibility of desmosomes. Nature Rev. Mol. Cell Biol. 5, 271-281. https://doi.org/10.1038/nrm1356

Green KJ, Simpson CL (2007): Desmosomes: new perspectives on a classic. J. Invest. Dermatol. 127, 2499-2515. https://doi. org/10.1038/sj.jid.5701015

Hatsell S, Cowin P (2001): Deconstructing desmoplakin. Nat. Cell Biol. 3, E270-272. https://doi.org/10.1038/ncb1201-e270

Kartasova T, Roop DR, Holbrook KA, Yuspa SH (1993): Mouse differentiation-specific keratins 1 and 10 require a preexisting keratin scaffold to form a filament network. J. Cell Biol. 120, 1251-1261. https://doi.org/10.1083/ jcb.120.5.1251

Ku NO, Liao J, Chou CF, Omary MB (1996) Implications of intermediate filament protein phosphorylation. Cancer Metastasis Rev. 15, 429-444. https://doi.org/10.1007/BF00054011

Labudova M, Tomaskova J, Skultety L, Pastorek J, Pastorekova S (2009): The nucleoprotein of lymphocytic choriomeningitis virus facilitates spread of persistent infection through stabilization of the keratin network. J. Virol. 83, 7842-7849. https://doi.org/10.1128/JVI.00309-09
Labudova M, Ciampor F, Pastorekova S, Pastorek J (2018): Cell-tocell transmission of lymphocytic choriomeningitis virus MX strain during persistent infection and its influence on cell migration. Acta Virol. 62, 424-434. https://doi. org/10.4149/av $2018 \quad 411$

Laposova K, Oveckova I, Tomaskova J (2017): A simple method for isolation of cell-associated viral particles from cell culture. J. Virol. Methods 249, 194-196. https://doi.org/10.1016/j. jviromet.2017.09.014

Macikova I, Perzelova A, Mraz P, Steno J, Bizik I, 1999. Heterogeneity of keratin intermediate filaments expression in human glioma cell lines. Neoplasma 46, 390-393.

Matloubian M, Somasundaram T, Kolhekar SR, Selvakumar R, Ahmed R (1990): Genetic basis of viral persistence: single amino acid change in the viral glycoprotein affects ability of lymphocytic choriomeningitis virus to persist in adult mice. J. Exp. Med. 172, 1043-1048. https://doi. org/10.1084/jem.172.4.1043

McLean WH, Lane EB (1995.): Intermediate filaments in disease. Curr. Opin. Cell Biol. 7, 118-125. https://doi. org/10.1016/0955-0674(95)80053-0

Meyer BJ, Southern PJ (1997): A novel type of defective viral genome suggests a unique strategy to establish and maintain persistent lymphocytic choriomeningitis virus infections. J. Virol. 71, 6757-6764.

Moll R, Franke WW, Schiller DL, Geiger B, Krepler R (1982): The catalog of human cytokeratins: patterns of expression in normal epithelia, tumors and cultured cells. Cell 31, 11-24. https://doi.org/10.1016/0092-8674(82)90400-7

Nishikawa J, Kiss C, Imai S, Takada K, Okita K, Klein G, Szekely L (2003): Upregulation of the truncated basic hair keratin 1(hHb1-DeltaN) in carcinoma cells by Epstein-Barr virus (EBV). Int. J. Cancer 107, 597-602. https://doi. org/10.1002/ijc.11289

Pastorekova S, Zavadova Z, Kostal M, Babusikova O, Zavada J (1992): A novel quasi-viral agent, MaTu, is a twocomponent system. Virology 187, 620-626. https://doi. org/10.1016/0042-6822(92)90464-Z

Reiserová L, Kaluzová M, Kaluz S, Willis AC, Závada J, Závodská E, Závadová Z, Ciampor F, Pastorek J, Pastoreková S (1999): Identification of MaTu-MX agent as a new strain of lymphocytic choriomeningitis virus (LCMV) and serological indication of horizontal spread of LCMV in human population. Virology 257, 73-83. https://doi. org/10.1006/viro.1999.9638

Roig J, Traugh JA (2001): Cytostatic p21 G protein-activated protein kinase gamma-PAK. Vitam. Horm. 62, 167-198. https:// doi.org/10.1016/S0083-6729(01)62004-1

Salvato M, Shimomaye E, Southern P, Oldstone MB (1988): Viruslymphocyte interactions. IV. Molecular characterization of LCMV Armstrong (CTL+) small genomic segment and that of its variant, Clone 13 (CTL-). Virology 164, 517-522. https://doi.org/10.1016/0042-6822(88)90566-1

Schafer IJ, Miller R, Stroher U, Knust B, Nichol ST, Rollin PE (2013): Notes from the field: a cluster of lymphocytic choriomeningitis virus infections transmitted through organ transplantation-Iowa, 2013. Am. J. Transplant. 14, 1459. https://doi.org/10.1111/ajt.12802 
Schmidt A, Jager S (2005): Plakophilins--hard work in the desmosome, recreation in the nucleus? Eur. J. Cell Biol. 84, 189-204. https://doi.org/10.1016/j.ejcb.2004.12.020

Sherer NM, Mothes W (2008): Cytonemes and tunneling nanotubules in cell-cell communication and viral pathogenesis. Trends Cell Biol. 18, 414-420. https://doi.org/10.1016/j. $\underline{\mathrm{tcb} .2008 .07 .003}$

Steinert PM, Roop DR (1988): Molecular and cellular biology of intermediate filaments. Annu. Rev. Biochem. 57, 593-625. https://doi.org/10.1146/annurev.bi.57.070188.003113

Sullivan BM, Emonet SF, Welch MJ, Lee AM, Campbell KP, de la Torre JC, Oldstone MB (2011): Point mutation in the glycoprotein of lymphocytic choriomeningitis virus is necessary for receptor binding, dendritic cell infection, and long-term persistence. Proc. Natl. Acad. Sci. USA 108, 2969-2974. https://doi.org/10.1073/pnas.1019304108

Tomaskova J, Labudova M, Kopacek J, Pastorekova S, Pastorek J (2008): Molecular characterization of the genes coding for glycoprotein and L protein of lymphocytic choriomeningitis virus strain MX. Virus Genes 37, 31-38. https://doi. org/10.1007/s11262-008-0240-2
Tomaskova J, Oveckova I, Labudova M, Lukacikova L, Laposova K, Kopacek J, Pastorekova S, Pastorek J (2011): Hypoxia induces the gene expression and extracellular transmission of persistent lymphocytic choriomeningitis virus. J. Virol. 85, 13069-13076. https://doi.org/10.1128/ JVI.00829-11

van der Zeijst BA, Bleumink N, Crawford LV, Swyryd EA, Stark GR (1983) Viral proteins and RNAs in BHK cells persistently infected by lymphocytic choriomeningitis virus. J. Virol. 48, 262-270.

Weber KL, Bement WM (2002): F-actin serves as a template for cytokeratin organization in cell free extracts. J. Cell Sci. 115(Pt 7), 1373-1382.

Wilkes MC, Murphy SJ, Garamszegi N, Leof EB (2003): Celltype-specific activation of PAK2 by transforming growth factor beta independent of Smad2 and Smad3. Mol. Cell Biol. 23, 8878-8889. https://doi.org/10.1128/ MCB.23.23.8878-8889.2003

Zavada J, Zavadova Z (1991): An unusual transmissible agent MaTu. Arch. Virol. 118, 189-197. https://doi. org/10.1007/BF01314029 